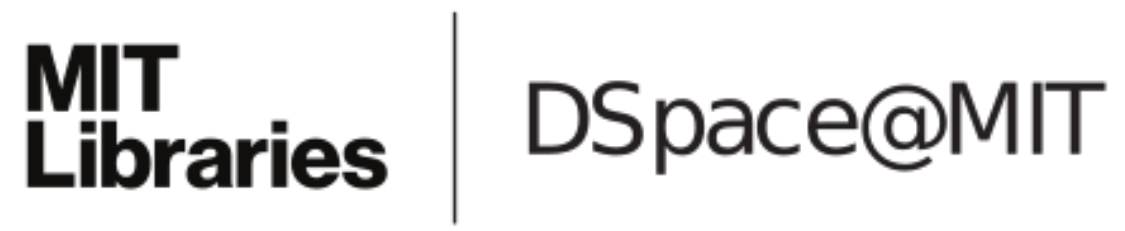

MIT Open Access Articles

Structure-function-property-design

interplay in biopolymers: Spider silk

The MIT Faculty has made this article openly available. Please share how this access benefits you. Your story matters.

Citation: Tokareva, Olena et al. "Structure-function-property-design Interplay in Biopolymers: Spider Silk.” Acta Biomaterialia 10, 4 (April 2014): 1612-1626 (c) 2013 Acta Materialia Inc

As Published: http://dx.doi.org/10.1016/J.ACTBI0.2013.08.020

Publisher: Elsevier BV

Persistent URL: http://hdl.handle.net/1721.1/117171

Version: Author's final manuscript: final author's manuscript post peer review, without publisher's formatting or copy editing

Terms of use: Creative Commons Attribution-NonCommercial-NoDerivs License 


\title{
Structure-Function-Property-Design Interplay in Biopolymers: Spider Silk
}

\author{
Olena Tokareva1,\&, Matthew Jacobsen², Markus Buehler ${ }^{3}$, Joyce Wong ${ }^{2}$, and David L. \\ Kaplan ${ }^{1, *}$ \\ ${ }^{1}$ Department of Biomedical Engineering, Tufts University, Medford, Massachusetts 02155 USA \\ 2Department of Biomedical Engineering, Boston University, Boston, Massachusetts 02215 USA \\ ${ }^{3}$ Department of Civil and Environmental Engineering, Massachusetts Institute of Technology, \\ Cambridge MA 02139 USA
}

\begin{abstract}
Spider silks have been a focus of research for almost two decades due to their outstanding mechanical and biophysical properties. Recent advances in genetic engineering have led to the synthesis of recombinant spider silks, thus helping to unravel a fundamental understanding of structure-function-property relationships. The relationships between molecular composition, secondary structures, and mechanical properties found in different types of spider silks are described, along with a discussion of artificial spinning of these proteins and their bioapplications, including the role of silks in biomineralization and fabrication of biomaterials with controlled properties.
\end{abstract}

\section{Keywords}

Spider silk; proteins; secondary structure; self-assembly; genetic engineering

\section{Introduction}

The order Araneae (spiders) contains over 37,000 species that have ability to produce silk, a key protein for spider survival [1]. Spiders use silk for a variety of practical purposes including arresting a fall, swathing prey, building a web, lining burrows, or making egg cases [2,3]. Diverse uses of Araneae silks originate from the outstanding physical properties that are tailored for specific needs, resulting in variation of mechanical properties. Mechanical properties of spider silks have not yet been duplicated by man-made materials. For instance, major ampullate silk (also known as dragline silk) of Caerostris darwini has a maximum strength (the strength needed to break the fiber) of up to $1.7 \mathrm{GPa}$ that is in the range of that of high-tech materials. Nevertheless, man-made materials such as steel (1.5 GPa) and Kevlar (3.6 GPa) present higher strength and stiffness, the overall toughness (energy required to break the fiber) depends on the extensibility. In these terms, high-tech

(C) 2013 Acta Materialia Inc. Published by Elsevier Ltd. All rights reserved.

*CORRESPONDING AUTHOR: David L. Kaplan, Department of Biomedical Engineering, Tufts University, 4 Colby Street, Medford, MA 02155; USA, Phone: (617)626-3251; Fax: (617)627-3231; David.Kaplan@tufts.edu.

\&Published previously as O. S. Rabotyagova

Publisher's Disclaimer: This is a PDF file of an unedited manuscript that has been accepted for publication. As a service to our customers we are providing this early version of the manuscript. The manuscript will undergo copyediting, typesetting, and review of the resulting proof before it is published in its final citable form. Please note that during the production process errors may be discovered which could affect the content, and all legal disclaimers that apply to the journal pertain. 
fibers appear to be more brittle compared to the more extensible dragline threads making spider dragline silks the strongest material [4-6]. In addition to this, spider dragline silks are light-weight materials that can undergo supercontraction when hydrated [7]. On an equal weight basis, spider silk has a higher toughness (the amount of energy absorbed per volume before breakage) than steel and Kevlar due to extensibility [8,9]. Moreover the other types of silk demonstrate unique mechanical properties as well. For example, flageliform silk (also known as a capture spiral silk) is over ten times more extensible than dragline silk, on the other hand flageliform silk is neither strong as nor as stiff than dragline silk[10]. Little force is required to extend flageliform silk $200-300 \%$ of its original length until the fiber gradually stiffens under the increasing strain. The remarkable mechanical properties of spider silks originate from their unique amino acid sequences that have remained almost unchanged for more than 100 million years[11]. Moreover, spider silk primary amino acid sequences have been shown to be organized in block (or domain) copolymer-like arrangements, in which two basic sequences, crystalline and less crystalline polypeptides alternate. At least seven different types of silk proteins are known for one species of spider [12]. They differ in primary sequence, physical properties and functions [1]. The complex spinning process, allows spiders to transform water soluble silk proteins into solid fibers at ambient temperature and pressure, giving rise to an environmentally safe, biodegradable, and high performance material [13-15].

Diverse and unique biomechanical properties together with biocompatibility and a slow rate of degradation make spider silks excellent candidates to be studied as biomaterials for tissue engineering, guided tissue repair and drug delivery, for cosmetic products (e.g. nail and hair strengthener, skin care products), and industrial materials (e.g., nanowires, nanofibers, surface coatings) [14-18]. A complete understanding of the anatomy of spider glands, the silk spinning process, and the role of silk primary structural elements and their contributions to the physical and biological properties of the biopolymer are important in order to fully understand the materials. Several reviews have focused on the structure and properties of spider silks, with the main focus on dragline silks [3, 16-19]. The structure-function relationships in other types of silk polymers are not as fully understood and this gap in knowledge can result in limitations in the use of these materials. In this review article, the goal is to provide information on the current understanding of the structure and properties of various types of spider silks with the main focus on the interplay among structure, architecture, and function, and how these attributes are being used in biomaterial designs.

\section{Anatomy and Physiology of the Spider Spinning Apparatus (Nephila clavipes)}

Orb web spiders produce silk in seven distinct pairs of glands. However, it is thought that all spider glands evolved from a single type of gland which diverged in anatomy, morphology and luminal content [20]. The presence of different amino acids in the luminal contents within each gland is responsible for the secretion of defined silk fibers with specific functions. Today, most research is focused on the major ampullate gland, which produces dragline silks.

In Nephila clavipes the silk formation glands are located within the abdomen of the spider and each type of gland occurs in pairs with bilateral symmetry [12]. The major ampullate gland can be schematically divided into four zones as shown in Figure 1: the tail zone, responsible for synthesis and secretion of spider silk proteins, the lumen (also known as the sac), involved in protein accumulation, the spinning duct responsible for the alignment of silk fibers, and the spigot for final fiber production [21]. 
The gland represents a reservoir of soluble silk proteins that are synthesized in specialized columnar epithelium cells in the tail zone and secreted into the lumen, where the proteins are stored as a highly concentrated liquid crystalline solution [22]. According to Vollrath and Knight [23], the tail zone is named the A-zone and the first part of the lumen is named the B-zone, based on the presence of the single type of cells known as the tall columnar secretory epithelium. The spinning duct follows the lumen, which is folded into an S-shape and narrows to the end [23]. Within this duct, silk proteins are present as liquid dope [22]. The spinning duct consists of three limbs. In each limb spidroin molecules have a different orientation. In the first limb, silk proteins are anchored perpendicular to the cuticle lining but parallel to each other [23]. In the second limb of the duct, silk molecules are bent in such a way allowing the formation of layered discs made up of the amphiphilic rod-shaped molecules that are still connected to the ducts cuticle lining. Finally, in the third limb the silk dope pulls away from the cuticle lining forming a draw down taper [22]. At this moment, the liquid silk solution is converted into a solid thread surrounded by water and it is thought that $\beta$-sheet formation is initiated during this process by means of the rapid extension flow that pulls silk molecules close together and aligns them using hydrogen bonding into $\beta$-sheets crystals $[24,25]$.

During the silk dope journey through the spinning duct, a number of changes in the chemical environment take place. These include lowing of $\mathrm{pH}$ from 6.9 in the first limb to 6.3 in the third limb, decreasing sodium and chloride concentrations, and increasing potassium, phosphate, and sulphate concentrations. At the same time, the drop in $\mathrm{pH}$ together with ionic changes can facilitate the neutralization of repulsive negative charges aiding silk molecule alignment into $\beta$-sheets. The final part of the major ampullate gland is represented by the valve and the spigot. The valve is used as a clamping device to control spider dragline and as a pump to remove threads that are broken inside the spigot. The spigot (spinneret) is located at the very end of the gland from which the spider thread is drawn. It has been proposed that the spigot is also capable of further modifying the silk thread [22].

Spider's threads are only produced when the spider physically moves away from one attachment point to another. A combination of elongation flow and wall shear within the gland creates tensile strain that induces $\beta$-sheet transitions in silk proteins as they pass through the fluid-to-solid transition zone (the taper). Higher tension imposes greater molecular alignment in the thread, making the silk stiffer, stronger and less extensible. Lower tension makes the silk less stiff, and weaker but more extensible. It should be noted that at higher temperatures, spiders move faster and therefore spin silk faster. Faster moving animals produce silk threads with different diameters and mechanical properties then compared to slower moving animals. When the silk protein is drawn from the spinning duct all the way down to the spigot, silk becomes progressively more dehydrated, slightly acidified, and birefringent, suggesting that the orientation and shape of silk molecules have been already programmed. Spiders can also apply a tension brake upstream from the valve that allows them to increase silk thread tension while the thread is still in the high humidity environment of the spigot. Figure 2 depicts the natural spinning process in spider.

\section{Spider Silk Types and Their Modules}

One spider is capable of producing up to seven different types of silks with varying mechanical properties. Silks are produced in specialized glands including the major and minor ampullate, tubuliform, flagelliform, aggregate, pyriform, and aciniform [21]. Spiders use their silk for a variety of practical purposes including: arresting a fall, swathing a prey, building a web, lining burrows, or making egg cases. Figure 3 depicts silk glands, silk types and silk functions of Nephila clavipes. 


\subsection{Major Ampullate Silk Proteins}

The golden orb weaver spider, Nephila clavipes, produces dragline silk in the major ampullate gland [26]. The protein complex is composed of major ampullate dragline silk protein 1 (MaSp1) and major ampullate dragline silk protein 2 (MaSp2). In $1990 \mathrm{Xu}$ and Lewis screened a cDNA library with a probe based on a short peptide isolated from acid hydrolyzed $N$. clavipes dragline silk and found the gene encoding MaSp1 [27]. The total length of MaSp1 transcript is $12.5 \mathrm{~kb}$ [28]. Analysis of the primary sequences of MaSp1 from different species revealed regular small peptide motifs that can be grouped into three categories: poly-alanine domains (poly(A/GA), glycine-rich domains (GGX), and nonrepetitive $\mathrm{N}$ - and $\mathrm{C}$-termini [1]. Additional studies [28] demonstrated that the poly-alanine regions can contain between four to seven alanine residues and the $\mathrm{X}$ position in the GGX repeat can be occupied only by $\mathrm{Y}, \mathrm{L}$ or $\mathrm{Q}$. Figure 4 depicts the repeating protein units of MaSp1 revealed by $\mathrm{Hu}$ and Lewis [27].

MaSp2 possesses similar structural motifs compared to MaSp1. It is composed of poly(A) and poly(GA), GPGGX domains, and non-repetitive N-terminus and C-termini. The main difference between MaSp1 and MaSp2 is the presence of proline $(\mathrm{P})$ residues accounting for $15 \%$ of the total amino acid content in MaSp2 [1]. MaSp1 is proline-free. By calculating the number of proline residues in $N$. clavipes dragline silk, it is possible to estimate the fiber content; 81\% MaSp1 and 19\% MaSp2 [29]. Different spiders have different ratios of MaSp1 and MaSp2. For example, a dragline silk fiber from the orb weaver Argiope aurantia contains $41 \%$ MaSp1 and 59\% MaSp2 [30]. Such changes in the ratios of major ampullate silks can dictate the performance of the silk fiber [23].

The sizes of the mRNAs and genes encoding these proteins have been determined, with the mRNA sizes for MaSp1 and MaSp2 approximately 12.5 and $10.5 \mathrm{~kb}$, respectively, generating a protein complex with the molecular weight of $350 \mathrm{kDa}$ [1]. $N$. clavipes uses MaSp1 and MaSp2 to build web frames and safety-lines. Another spider, Araneus diadematus, produces analogous MaSp1 and MaSp2 proteins known as ADF-3 and ADF-4 that possess similar structural motifs and perform similar functions [9]. In addition, a genomic library for the black widow spider, Latrodectus hesperus (Theridiidae) was constructed in order to identify full-length silk genes and regulatory regions [31]. The gene sequences of MaSp1 and MaSp2, as well as adjacent non-coding regions, were identified. The existence of higher-order repeat units that range from 70 to over 2,000 bp was revealed; and the authors showed that the repetitive sequences of MaSp1 were more homogeneous than those of MaSp2. In addition to the repetitive domains, dragline silks contain nonrepetitive $\mathrm{N}$ and $\mathrm{C}$-termini [27] [32]. The length and amino acid composition of the Ctermini are conserved between major ampullate proteins from different spiders and the $\mathrm{C}$ terminal region is important for solubilizing silk proteins in the highly concentrated spinning dope [1]. In contrast to the C-terminus, little is known about the $\mathrm{N}$-terminal region of spider silks. The sequence possesses an enzymatic cleavage site, has an usual amino acid composition and may include a signal peptide [25].

\subsection{Minor Ampullate Silk Proteins}

Minor ampullate silk may be particularly interesting for biomedical applications since it is strong and does not supercontract in water (note: NMR data show some structural changes) $[33,34]$. The minor ampullate silk from $N$. clavipes consists of two distinct proteins, the minor ampullate dragline silks 1 and 2 (MiSp1 and MiSp2), with transcripts of 9.5 and 7.5 $\mathrm{kb}$, respectively, generating proteins of $320 \mathrm{kDa}$ and $250 \mathrm{kDa}$ [28]. The cDNA sequence representing the MiSp1 transcript from $N$. clavipes was published shortly after the initial discovery of the MaSp1 sequence [35]. Figure 5 shows the consensus repeats found in MiSp1 and MiSp2 from N. clavipes. 
The minor ampullate dragline silk proteins possess similar structural domains to the major ampullate silk proteins; however, there are some differences. The similarities include the presence of GGX and poly(A) modules. However, poly(A) modules of the MaSps are replaced by poly(GA) repeats [33]. The organization of modules is also similar to MaSps; whereas, the number of repeats is different. Another difference is the presence in MiSps of a conserved serine (S)-rich non-repetitive 137 amino acid sequence that is termed a spacer region [35]. The spacer regions have a similar serine composition relative to the amorphous regions of Bombyx mori and are highly conserved among different spider species. It is hypothesized that the spacer plays a role in fiber formation by serving as a site of proteinprotein interactions. Recently, a full-length minor ampullate spidroin gene sequence was obtained from the spider Araneus ventricosus using PCR [33]. Sequence alignment of spacer regions was performed; however, the functional role of this spacer remains to be determined.

\subsection{Flagelliform Silk Proteins}

The major component of the capture spiral of a spider web is flagelliform silk (Flag), which is produced by the flagelliform gland. Hayashi and Lewis retrieved a partial cDNA sequence of flagelliform silk from the $N$. clavipes flagelliform gland [36]. The flagelliform gene encodes an mRNA transcript of $15 \mathrm{~kb}$ that generates a protein of $\sim 500 \mathrm{kDa}$ [1]. Flagelliform silk has several distinctive features; a) GPGGX domain; b) highly conserved spacer with charged and hydrophilic amino acids; c) nonrepetitive C-terminal region [37]. Such a structural combination gives flagelliform silk high elasticity; it can stretch up to $200 \%$ of its own length. The GPGGX domain is thought to be responsible for the elasticity of flagelliform silk. This GPGGX domain was also found in MaSp2. Flagelliform silk has the same GPGGX repeat but it occurs seven times more in flagelliform than in MaSp2. Flagelliform silk exhibits seven times more elasticity than MaSp 2 [21]. The molecular mechanism of such elasticity is the formation of a molecular spring ( $\beta$-spiral), in which a series of type II $\beta$-turns are linked together. The spacer region has no homology with known proteins and the functions are unknown. Also unknown is the function of the C-terminal region, which shows no similarity to the C-termini of MaSps and MiSp [32] [38].

\subsection{Aciniform Silk Proteins}

Aciniform silks are used by araneoid orb-weavers, including Nephila clavipes, to wrap and immobilize prey, build sperm webs and for web decorations [1]. Aciniform silk contains only one protein, aciniform spidroin 1 (AcSp1), with 14 highly homogeneous repeats, with each ensemble repeat consisting of 200 amino acid domains [39]. AcSp1 has a low percentage of $\mathrm{G}$ and A relative to dragline silk and possess a C-terminal domain that has little similarity with major ampullate, minor ampullate or flagelliform silks. Moreover, the repetitive sequences predicted from the AcSp1 cDNA do not resemble iterations found within other spider silk proteins [39]. In terms of mechanical performance, aciniform silks have a lower tensile strength relative to dragline silks but higher extensibility and toughness. Based on the lack of these similarities aciniform silks likely represent divergent members of the silk gene family.

\subsection{Tubuliform (Eggcase) Silk Proteins}

Tubuliform silk (TuSp1) is produced by female spiders during the reproductive season to make egg cases. This silk type is secreted by the tubuliform (cylindrical) gland and has a distinct amino acid composition which is responsible for the unusual mechanical properties. Tubuliform silk has a relatively high tensile strength with a fairly low elasticity that makes it different from other silk types [40]. Protein sequences from three orb-weaving spiders, Argiope aurantia, Araneus gemmoides, and $N$. clavipes revealed that TuSp1 rarely show the four common spider silk motifs discussed earlier, GPGXX, GGX, poly-A, spacer. Instead, 
TuSp1 has a more complex architecture with different amino acid motifs such as $\mathrm{S} n$, (SA)n, (SQ)n, and GX (X represents Q, N, I, L, A, V, Y, F, or D) [41, 42]. The interesting feature is that tubuliform silk is also capable of forming $\beta$-sheets as a result of the structural domains, such as AAQAASAA, AAQAA, and AASQAA [42]. The presence of side chains in the silk modules $(\mathrm{Q}$ and $\mathrm{S})$ directs larger spacing among the formed $\beta$-sheets relative to the poly- $\mathrm{A}_{\mathrm{n}}$ ' $(\mathrm{GA})_{\mathrm{n}}$ model; this makes the tubuliform silk more hydrophilic [40]. The tubuliform Cterminal domain has no similarity with other silks and it is assumed that TuSp1 is evolutionary an ancient silk [42].

Only recently, two other proteins from egg case core fiber of $L$. hesperus were discovered [43]. They are called egg case protein 1 and 2 (ECP-1 and ECP-2). Analysis of the primary sequence of ECPs indicate similarity to dragline silks based on the presence of poly-A/(GA) modules [43]. As a result, it is now assumed that the core fiber of egg case silk is a trimeric complex consisting of TuSp1, ECP-1 and ECP-2, where TuSp1 serves as a core protein and ECPs function as intermolecular crosslinkers, with a potential structural role in an egg case fiber.

\subsection{Fiber Coating (Glue) and Pyriform Silk Proteins}

Little is known about fiber coating peptides and pyriform (alternative spelling: piriform) silks. Recently, Hu and coworkers have isolated the cDNAs of two distinct fiber coating proteins, which were named spider coating peptide 1 (SCP-1) and spider coating peptide 2 (SCP-2), respectively [44]. Secreted forms of SCP-1 and SCP-2 contain 36 and 19 amino acids, respectively, and their primary sequences display no similarities to the ensemble repeat units from traditional spidroins. Quantitative real-time PCR analyses showed that mRNAs of SCP-1 and SCP-2 are produced by the aggregate gland. In addition to this, extensive expression studies have also revealed that $L$. hesperus, commonly referred to as the black widow spider, is capable of producing large amounts of SCP-1 in the flagelliform gland[45, 46]. Biochemical studies demonstrated that the SCP-1 peptide has intrinsic metal binding properties, suggesting a role of peptide-metal ion interactions with the fiber constituents to enhance thread performance [44]. In L. hesperus the aggregate gland has also been shown to produce two different proteins, aggregate gland silk factor 1 (AgSF1) and aggregate gland silk factor $2(\mathrm{AgSF} 2)$ [47]. These proteins were found to be co-localized to the connection joints of both webs and wrapping silks spun from the black widow spider. Biochemical analysis revealed that AgSF1 and AgSF2 have different protein architectures compared to traditional spider silk family members. In case of AgSF1, the amino acid sequence analysis revealed the presence of pentameric QPGSG iterations that are similar to conserved modular elements within mammalian elastin. In case of AgSF2, the consensus novel repetitive sequence, NVNVN, was determined. The amino acid block repeats were found to be embedded in a glycine-rich matrix of AgSF2 [47]. Adhesive spider silk proteins (glues) are important members of the silk family that allow spiders to perform a variety of tasks, such as web construction, prey capture, and locomotion. More extensive studies are needed to reveal the primary structure, properties and functions of these silks among different spider species.

Pyriform (piriform) silk proteins are relatively newly discovered members of the spider silks family. They are components of the attachment discs, which lashes the joints of the web and attaches dragline silk to surfaces [48]. Recently, a novel member of the silk gene family, pyriform spidroin 1, was discovered in attachment discs of the black widow spider, $L$. hesperus [49]. Alignment of the PySp1 amino acid sequence to other fibroins revealed conservation in the non-repetitive C-terminal region of the silk family. Scanning electron microscopy studies revealed the presence of small diameter fibers embedded in a glue-like cement that formed a continuous network with large diameter dragline silk threads, 
producing a strong, adhesive material. The pyriform silk is produced by the pyriform gland and it is used for attachments and for joining spider threads. The amino acid composition has been determined using luminal gland materials from orb-weaver spiders and it was found that pyriform silk contains very polar amino acids, such as S, D, E, L, T, and N [20]. The precise molecular identities of the proteins involved in both silks remain to be determined. Recently, pyriform spidroin 2 (PySp2) was discovered within the attachment discs of $N$. clavipies by Geurts and coworkers [50]. Biochemical studies revealed that PySp2 contains internal block repeats that consist of two subrepeat units: SQA-rich and P-rich. Artificial spinning of recombinant PySp2 truncations shows that the SQA-rich subrepeat is sufficient for the assembly of polymeric subunits and subsequent fiber formation. These studies support that both orb- and cob-weaving spiders have evolved highly polar blockrepeat sequences with the ability to self-assemble into fibers, suggesting a strategy to allow fiber fabrication in the liquid environment of the attachment discs[50].

In conclusion, the relationships between the core silk sequences and all of their roles in spider survival remain unclear. Additional studies are required to elucidate the silk sequences for a variety of orb weaver and cob weaver spiders. Table 1 summarizes the domains and core units found in different spider silk types. This table also provides information regarding the structure of aciniform (AcSp1), tubuliform (TuSp1), and pyriform (SCP1 and 2) silks.

\section{Secondary Structure Elements of Silk Proteins}

The outstanding physical properties of major ampullate dragline silks originate from the protein primary sequences, where hydrophilic terminal domains flank large central hydrophobic domains [51]. Spider silk proteins and their genes are only partially characterized; however, it is generally concluded that most of the spider silks are made up

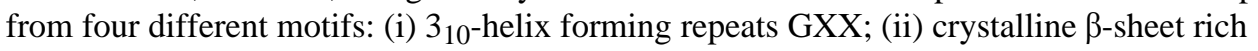
poly(A)/poly(GA) motifs, (iii) an elastic beta-spiral region, also known as proline-rich region, composed of multiple GPGXX motifs; and (iv) a spacer region with unknown functions. These motifs appear to be conserved among different species and are found in orthologs of cDNAs from other Araneus genera [52]. The silk protein secondary structure arises from the interplay between spider silk key elements, namely A-rich and GA-rich motifs. This interplay leads to the formation of both helical structures $\left(3_{10}\right.$-helices, ahelices, PP II helices) or $\beta$-sheet structures that are responsible for the physical properties of spider silks as well as the explanation of the rapid fiber formation $[9,22]$.

The majority of studies on spider silks have been focused on the major ampullate dragline silks due to a unique combination of elastic and tensile properties. The studies established that dragline silks contain extended, ribbon-like $\beta$-sheets that are oriented parallel to the fiber axis, $\beta$-turns and helices [39]. Poly(A) and poly(GA) regions are responsible for the fiber tensile strength due to the formation of crystalline $\beta$-sheets. Poly-A repeats form a $\beta$ sheet conformation in which each A residue is placed on alternative sides of a backbone [28, 38]. The hydrophobic interactions that arise from such conformation connect poly(A) chains together by protruding methyl groups occupying the void space near the alpha carbon of a residue on a neighboring chain. As a result, $\beta$-sheets are poorly hydrated, have no void space, and are impenetrable to water. The poly(GA) regions form a similar structure, but with a different hydrophobic pattern. The glycine side chain is unable to form the same hydrophobic interactions as the A side chain resulting in fewer links in the $\beta$-sheet structure. Figure 6 depicts the comparison between poly(A) and poly(GA) domains.

Computer models for two antiparallel strands of the poly(A) and poly(GA) motifs are shown. Note a large vacant area in the poly $(\mathrm{GA})$ when compared with the poly(A) strands. 
A difference in hydrophobic pattern in the poly $(\mathrm{GA}) \beta$-sheets compared to poly(A) $\beta$-sheets results in lower tensile strength of the minor ampullate silks (poly(GA) module) relative to the major ampullate silks (poly(A) module). The primary structure dictates the strength of interactions between $\beta$-sheets, which in turn determines in part the tensile strength of the silk fibers generated from these proteins. Poly(A) sequences have been shown to form a Poly(P) II helix in the unfolded state [12,53], whereas in the folded state they form $\beta$-sheet aggregates [8]. These findings can explain the spider silk liquid state in the silk gland and its transition to a solid fiber.

NMR studies conducted by Holland and colleagues showed that water affects the mechanical properties of a silk fiber [34]. MaSp 1 and MaSp 2 have different interactions with water. After hydration significant chain motion occurs in the GGX regions and the alanine regions which have a tendency to form a helix (Figure 6). It is thought that the mobile A regions observed by NMR are able to participate in the connections between the crystalline and amorphous domains in a silk fiber $[34,54,55]$. The appearance of the mobile regions can also facilitate crystal reorientation in the silk fiber that is observed by fiber Xray diffraction. It is thought that the GAG repeats that terminate the poly(A) runs are these mobile A regions [54]. The mobility of GAG repeats together with GGX repeats is an explanation for the increased extensibility and decreased stiffness observed for wet, supercontracted, dragline silks. It has been postulated that the mobility of these repeats is a reversible process [34]. The reversible conversion of GGX protein segments between the $\beta$ sheet and helical conformation provides the driving force for the supercontraction in MaSp1 silks [56]. However, in other silk types where GPGXX sequences dominate over GGX sequences, supercontraction is likely due to the recruitment of kinetically free (i.e. rubberlike) domains made from the GPGXX repeats. When $\beta$-sheets are formed, they have a certain size that also influences the mechanical properties of silks. Spin-diffusion NMR experiments estimate that the average poly(A) crystalline domain is about $6 \pm 2 \mathrm{~nm}$ [34], in agreement with WAXS data on dry silks [21]. Additionally, the size of the $\beta$-sheet crystallites does not change after contact with water due to the nonpolar and hydrophobic nature of poly(A) that reinforce crystal stability by preventing water diffusion between stacks of $\beta$-sheets [57]

The second element, the GGX segment, has been proposed to form either a $\beta$-sheet or $\alpha$ helix structure (Hayashi et al., 1999). FTIR and NMR data support the helical conformation of the GGX repeats [58]. The GGX segment is a tight three amino acid repeat that assumes a poly(G)PII helix based on molecular modeling [58]. Figure 7 depicts the computer model of the GGYGGLGGQGGA repeat [12].

The hydrophobic core of this structure is composed of methylene groups, while tyrosine (Y) and glutamine $(\mathrm{N})$ residues form the hydrophilic shell through hydrogen bonding. By forming the hydrophobic core, the $\mathrm{G}$ residues provide stabilization to fiber formation. The GGX helices can also serve as a link between crystalline $\beta$-sheets within the protein and between neighboring GGX helices in adjacent protein molecules facilitating fiber alignment [59]. The GPGXX segment found in MaSp2 is proposed to be responsible for the extensibility of dragline silks, forming $\beta$-turns that participate in the formation of a $\beta$-spiral. [28]. Figure 8 depicts a computer model of the silk $\beta$-spiral. These proline-rich pentapeptide blocks contribute to the extensibility of spider silks and are largely responsible for the high toughness of MaSp silks. More studies are needed to fully understand the secondary structure of GPGXX blocks and its role in silk's extensibility.

The $\beta$-spiral spring serves as the elastic mechanism in the silk fiber; namely, by simple extension and contraction of the $\beta$-spiral, a silk fiber exhibits elasticity. Hayashi et al. (1999) and Lewis (2006) suggest two key features of this model. First, the presence of P residues 
provides focal points for the retraction of energy after stretching. Thus, when forcing the $\mathrm{P}$ bonds to torque in response to extension, a large retraction force is generated. The second key feature is that the positions of $\mathrm{S}$ and $\mathrm{Y}$ hydroxyls allow them to form hydrogen bonds with downstream $\mathrm{G}$ residues, where the longer $\mathrm{Y}$ side-chains stabilize the tight $\beta$-turns and the shorter $\mathrm{S}$ side-chains stabilize the layers of coils. The importance of these bonds is supported by the strong tendency for $\mathrm{Y}$ and $\mathrm{S}$ residues to regularly alternate in flagelliform silk. Only two silk types possess the GPGXX segment, the major ampullate spidroin 2 and flagelliform silks [60]. Further support of the role of the GPGXX segment is provided by the correspondence between the number of GPGXX repeats in one molecule and the different extensibilities of the two silks. The wet major ampullate silk has up to $35 \%$ extension when $\beta$-turns occur nine times in a row before being interrupted by another motif [5]. Flagelliform wet silk has $200 \%$ extensibility and has at least 43 contiguously linked $\beta$-turns in its springlike spirals [36]. More experimental and computational studies are needed to fully understand the secondary structure of GPGXX blocks and its role in silk's extensibility. Little is known about the structures formed by the spacer regions of the minor ampullate and flagelliform silks. The only available information is that spacers are long, highly conserved among spiders, non-repetitive and rich in serine [22]. Figure 9 summarizes the secondary structure and core modules found in orb-weaver spider silks.

The primary sequence domains found in spider silks determine the biological, chemical and physical properties of silk fibers. By knowing the role of each structural element, it is possible to predict properties of silks. For example, by increasing the number of poly(A) repeats in a given peptide the resulting fiber will likely have higher tensile strength than those peptides containing poly(GA) repeats. The presence of the GPGXX motif give rise to a $\beta$-spiral spring that is responsible for the extensibility of silk-like polymers. Finally, GGX regions can be present as transition domains between different types of structural regions facilitating self-assembly. In summary, it can be concluded that a few amino acid motifs or domains found in spider silks give rise to the tremendous diversity of silks that has evolved through the modification and rearrangement of these motifs. These few amino acid motifs directly determine the complex array of mechanical properties exhibited by silk proteins.

\section{Mechanical Properties of Spider Silks}

The orb-weaving spiders produce a variety of high-performance fibers with mechanical properties that outperform synthetic materials in the combination of strength and elasticity. Dragline silks form extremely strong fibers. Dragline silk tensile strength is comparable to Kevlar and it has extensibility which is seven times greater than the extensibility of Kevlar $[18,61]$. This combination of features makes major ampullate silk one of the toughest materials known [5, 62]. Minor ampullate silk is similar to major ampullate silk in tensile strength but has limited elastic behavior. However, flagelliform silk has outstanding extensibility, stretching as much as $200 \%$ and, at the same time, it is a strong fiber [38]. Table 2 summarizes the strength, elasticity and energy to break values for known spider silks along with selected biomaterials and man-made materials [63].

Spider silks are a useful fiber model to study relationships between sequence chemistry, secondary structure and mechanical properties in protein-based materials and are excellent candidates for biomaterials.

\section{Spider Silk Processing - Artificial Modes to Mimic Nature}

The development of genetic recombination techniques has opened the possibility to reproduce the silk spinning process in an in vitro environment. However, many of the desirable mechanical properties of the various spider silks are a result of the higher order 
protein structures [64] that result from specific processing of the primary protein sequences that occurs in the silk gland. Therefore, reconstitution of primary spidroin protein sequences into functional fibers has emerged as a topic of great interest for many materials and tissue engineering applications where the high strength, extensibility and toughness intrinsic to natural silk are ideal. This challenge has led to efforts to adapt processing techniques to mimic the natural spinning process in order to promote improved protein configuration in the secondary structure, which primarily refers to the formation and alignment of $\beta$-sheets. Techniques that simulate the mechanistic changes that occur during the spinning process are largely performed by rate-controlled extrusion directly through a syringe. Figure 10 depicts a light microscope bright field image of fibers spun from recombinant spider silk. Important elements that improve overall fiber formation and $\beta$-sheet quantity and alignment are common among the many variations of this basic extrusion method.

First, initial solvents of the spidroin proteins need to exhibit strong hydrogen bonding characteristics to improve solvent-protein interactivity and solubility, making distilled water and hexafluoroisopropanol (HFIP) good candidates. Improved solubility allows for higher concentrations of dope, which has shown greater success in fiber formation [65, 66]. Next, shearing of the silk dope with the wall of the tubing through which the dope is flowed initiates protein alignment, which has been shown to be a major factor in the spider major ampullate glands [67]. Then, extrusion into a miscible organic solvent, such as methanol or isopropanol, has been shown to help induce fiber formation through dehydration of the silk sequence $[68,69]$. And lastly, drawing the newly formed fiber to cause strain elongation has shown to induce higher $\beta$-sheet content and improve overall mechanical properties of the silk including elastic modulus, toughness, elongation to failure, and ultimate strength [70, 71]. Current applications using these techniques have produced fibers with diameters in the range of $10-60 \mu \mathrm{m}$ and ultimate strengths between $60-160 \mathrm{MPa}$, which is still lacking in comparison against native major ampullate fibers with diameters in the range of $2.5-4 \mu \mathrm{m}$ and failure strengths typically in the 1-2 GPa range.

While these drawn synthetic fibers exhibit improved mechanical properties for synthetic sequences, these values are still well below the measured properties of the native structures, which encourages the discussion of ways to improve the structural integrity of synthetically derived spidroin sequences. Some strategies have included elongating the polymeric repeat structure of the hydrophilic and hydrophobic blocks in synthetic constructs to promote greater chain-chain interactivity. Increasing hydrophobic chain length has been modeled and reported to increase $\beta$-sheet crystallinity at the molecular level [72] and experimental evidence has been presented that show stronger materials resulting from longer polymeric sequences [70]. Other strategies include the incorporation of the characteristic $\mathrm{pH}$ gradient of the natural spinning duct using microfluidics [71]. This offers the added advantage of microfluidic control over final fiber dimensionality based on laminar flow parameters of the spinning device, which additionally mimic the volumetric tapering of the spinneret.

However, this technique must be balanced against the loss of shearing at the boundary of the channel that is important in initial fiber formation.

Apart from techniques to mimic spinning gland mechanisms in an effort to generate biomimetic micron-scale fibers, there is also interest in using silk as a functional surface itself. This is accomplished through electrospinning the purified spidroin or fibroin dopes onto a surface, which generates a nonhomogeneous fiber mesh comprised of submicron features [73]. This technique is appealing for biomaterial applications because of the feasibility of electrospinning and the fiber mesh customization that is possible. Figure 11 depicts electrospun fibroin. 
Modifications, such as the addition of other proteins into the silk dope, can affect the bulk characteristics of the mesh. Some reported examples include the addition of carbon nanotubes in order to increase fiber elastic modulus [74], addition of poly(lactic acid) (PLA) and poly(glycolic acid) (PGA)to incorporate more hydrolysable motifs [75], and incorporation of various growth and/or chemical factors for applications in neuron [76, 77], cardiovascular [78], skin [79], and bone [80] engineering to name a few. Fibers generated in this fashion range in diameter from $0.2-2.5 \mu \mathrm{m}$, which are a closer approximation dimensionally than extruded fibers, but proportionally lack the extruded fibers' tensile strength with failures occurring in the $0.5-4 \mathrm{MPa}$ range.

To summarize, fiber generation can be tuned based on the scaling and properties desired with fiber diameter ranges from hundreds of nanometers to tens of microns. The former is yielded in an unwoven mesh of nano- to micro-scale fibers that has a variable, collective behavior based on spinning composition. The latter is yielded in discrete, individual fibers that are able to be manipulated by hand. Many of these techniques are universally applicable to the known varieties of silk; however, more investigative effort has been invested in optimizing techniques that employ Bombyx mori fibroin proteins. While there are strong correlates and results that have bearing for spider fibroin and spidroin-based fiber processing applications, it may be necessary to focus specifically on the unique mechanisms that differentiate the two silk-spinning organs and organisms in order to maximize the properties of the processed materials for ongoing and future synthetic spidroin-based fibers and fiber networks.

\section{Spider Silks in Biomaterial Design}

\subsection{Spider Silk Block Copolymers}

Block copolymers are a fascinating family of polymeric materials usually prepared by the covalent bonding of two or more thermodynamically incompatible polymeric or oligomeric chains that give rise to a variety of nanostructure morphologies in solution and in bulk [81]. Nanostructure formation by synthetic block copolymers is the focus of many studies, while biologically derived systems have been less studied [82]. Silks are natural block copolymers with a characteristic crystalline $\beta$-sheet secondary structure encoded by hydrophobic peptide blocks. $\beta$-sheets form through natural physical crosslinks of amino acid sequences, which in spider and silkworm silks consist of multiple repeats of mainly alanine, glycine-alanine, or glycine-alanine-serine, as described in some detail earlier in this review. The hydrophilic, non-crystalline regions of silk commonly consist of: (i) $\beta$-spirals similar to a $\beta$-turn composed of GPGXX repeats (where $\mathrm{X}$ is mostly glutamine) and (ii) helical structures composed of GGX [12]. Inspired by the extraordinary material properties of spider silks, a family of spider silk block copolymers was designed and bioengineered based on the assembly of individual spider silk domains, in particular poly-alanine (A) and glycine-rich (B) domains, that display different phase behavior in aqueous solution [83, 84]. The interplay between the silk block copolymer sequence, composition, length and self-assembly behavior was assessed to build materials with precise structural and morphological features [83]. The A block consisted of one polyalanine/polyglycine repeat (GAGAAAAAGGAG) that is responsible for $\beta$-sheet formation. The B block was composed of four GGX repeats, separated by the GSQGSGR sequence. The GGX repeats adopted a helical conformation and served as a hydrophilic link between crystalline $\beta$-sheet regions as well as neighboring GGX helices in adjacent protein molecules that helped reinforce fiber alignment. Secondary structure and morphology were assessed by FTIR and SEM, respectively. Based on these analyses, trends in block copolymer assembly behavior into specific morphologies were observed as a function of the number of hydrophobic blocks (A) and solvent effects. In terms of structure, as the size of the hydrophobic block increased, the content of $\beta$-sheet increased in the silk block copolymers. In terms of morphological features, the increase in 
hydrophobicity (increase in the number of A blocks) was connected with a transformation from thin films to micelles $(1-3 \mu \mathrm{m})$ and finally to large compound micelles $(50 \mu \mathrm{m})$ in water. In terms of solvent selection, when 2-propanol was the solvent, a transformation from thin films to nanofibers (50-200 nm) and large compound micelles was observed (Figure 12). Further studies characterized the thermal properties and demonstrated the self-assembly of monolayers of spider silk-like block copolymers [85]. At high surface pressure, spider silk block copolymers with minimal hydrophobic domains (BA) formed oblate structures, whereas block copolymers with a 6-fold larger hydrophobic domain (BA6) formed prolate structures [86]. The study provided a basis for future designs of biomaterials based on spider silk chemistry, with controlled structure-architecture-function relationships. In addition, the observed nanofiber and compound micelle architectures are potentially useful for biomedical applications and could be employed as drug delivery reservoirs, tissue scaffolds and environmental friendly polymers.

Recently, a pH-responsive silk-like block copolymer with a sequence of $\left.\left[(\mathrm{GA})_{3} \mathrm{GE}(\mathrm{GA})_{3} \mathrm{GL}\right)\right]_{28}$ was produced in the yeast Pichia pastoris at the $\mathrm{g} / \mathrm{L}$ level [87]. As a model peptide, a silk-like peptide $\left(\left[(\mathrm{GA})_{3} \mathrm{GE}(\mathrm{GA})_{3} \mathrm{GE}\right]_{24}\right)$ known to be water soluble above the isoelectric point and formed insoluble stacks of $\beta$-sheets in a dried state [88]. Every second octapeptide had a hydrophobic $L$ residue in place of $E$. This change made the peptide more amphiphilic [87]. The block copolymer formed fibers upon crystallization in $70 \%$ (v/v) formic acid under vapor diffusion of methanol, as shown by AFM, with the average fibril height of $2.7 \mathrm{~nm}$ and width of $49 \mathrm{~nm}$. The CD spectrum of the negatively charged polymer in aqueous solution at high $\mathrm{pH}$ indicated a dominance of random and extended helical (silk III-like) structures, whereas the spectrum of a coating prepared from such a solution showed a conformation rich in $\beta$-turns. Given the biocompatibility of silk-like materials, the polymer may be of interest for biomedical applications, such as the coating of surgical implants or $\mathrm{pH}$-responsive controlled drug release.

The construction of a biosynthetic multiblock protein polymer based on the sequences of dragline silk from A. diadematus [(AEAEAKAK) $\left.{ }_{2} \mathrm{AG}(\mathrm{GPGQQ})_{6} \mathrm{GS}\right]_{9}$ was also reported [89]. The block copolymer spontaneously formed self-supporting macroscopic films via rearrangement of segments within the polypeptide from a-helices to $\beta$-strands. The primary structure of the polymer consisted of the amphiphilic peptide, (AEAEAKAK) $)_{2}$, that was capable of adopting a $\beta$-strand conformation over a wide range of $\mathrm{pHs}$ and temperatures. The glycine-rich segment, GPGQQ, was derived from A. diadematus dragline silk. The central PG unit in the glycine-rich block had a high propensity for the formation of type II $\beta$ turns. High resolution FESEM of cryo-immobilized, water-swollen membrane revealed a network of fibrils, approximately $10-20 \mathrm{~nm}$ in diameter, interspersed within a less structured matrix.

The formation of $\beta$-sheet structures induced irreversible aggregation of $\left[(\mathrm{AEAEAKAK})_{2} \mathrm{AG}(\mathrm{GPGQQ})_{6} \mathrm{GS}\right]_{9}$ polypeptide into a hydrogel network through interstrand hydrogen bonding interactions between chain segments [89]. The influence of the polypeptide structure on the physical properties of silk-like block copolymers using gel electrophoresis under denaturing conditions was investigated. The authors observed that the number of repetitive units, as well as side chain modifications (i.e., glycosylation, phosphorylation), significantly affected gel mobility. For example, negatively charged and carbamylated peptides showed low gel mobility then compared with unmodified peptides, positively charged and neutral polypeptides [90]. Ultimately, this block copolymer approach can provide a foundation for the design of highly engineered biomaterials for a range of important applications. 


\subsection{Spider Silk/Silkworm Fibroin Hybrids}

Silk-based biomaterials have attracted interest due to their mechanical and self-assembling properties in the biomaterial field. A unique combination of high elasticity, toughness, and mechanical strength, along with biological compatibility and biodegradability make silks advantageous candidates [59, 91, 92]. As mentioned earlier in this review, dragline silk from orb-weaving spiders is a copolymer of two large proteins, major ampullate MaSp1 and MaSp2. The ratio of these proteins is known to have large variation across different species of orb-weaving spiders resulting in different mechanical properties of silk fibers. For example, $N$. clavipes major ampullate silk contains $80 \%$ of MaSp1, whereas major ampullate silk of A. aurantia is comprised of only around 40\% MaSp1 [3, 29]. The question of how the ratio of MaSp1 and MaSp2 influence fiber formation and its mechanical properties has been studied, including using engineered MaSp1/MaSp2 mixed fibers as well as chimeric silk fibers from MaSp1 and MaSp2 sequences in a single protein [93]. Spun fibers were stretched in a 75\% isopropanol/water solution, as the as-spun fibers were semisoluble in water. The proteins with a higher molar ratio of the polyalanine motif formed fibers with higher tenacity and Young's modulus (about $10 \mathrm{MPa}$ higher in tenacity, $0.4 \mathrm{GPa}$ higher in Young's modulus, for stretched and as-spun fibers). The protein that contained more GPGXX motifs were more extensible [93].

In a similar study two chimeric proteins based on the sequences of Flag and MaSp2 silks of $N$. clavipes were produced [14]. The designed was based on dragline MaSp2, but (GPGQQ GPGGY $)_{2}$ was replaced with one of two Flag native variants. These chimeric Flag/MaSp2 chimeric proteins provided interesting self-assembly abilities in aqueous solution, triggered by heat and/or shear, depending on the nature of the Flag structural motif. Both of these proteins formed synthetic fibers in organic or aqueous conditions by extrusion or fiberdrawing from self-assembled films.

In a recent effort to develop tough fibers, transgenic silkworms encoding chimeric silkworm/ spider silk proteins were produced using piggyBac vectors [94]. The vector that was previously used by the Tamada group [95] included the Bombyx mori fibroin heavy chain promoter and enhancer, a gene sequencing encoding a $78 \mathrm{kDa}$ synthetic spider silk protein, and an enhanced green fluorescent protein (EGFP) tag. Strong EGFP signals were observed under a fluorescence microscope (Figure 13). The composite fibers were tougher than the parental silkworm silk fibers and as tough as native dragline spider silk fibers.

These results demonstrate that silkworms can be engineered to manufacture composite silk fibers containing stably integrated spider silk protein sequences, which significantly improved the overall mechanical properties of the silk fibers.

\subsection{Functionalization of Spider Silks with Fusion Peptides}

Biomineralization is the process found in nature by which biological organisms produce mineralized tissues such as bones, diatoms, shells and teeth [91, 96]. In biological organisms organic molecules exert remarkable level of control over the process of mineral formation, including the hierarchical organization and functional properties [97]. Through the use of recombinant DNA technology, a variety of novel materials can be engineered with properties not present in nature [81]. Since spider silks have desirable self-assembly characteristics, they can be used as molecular building blocks for the core structure together with desirable inorganic-binding peptides tailored for practical applications. Silk-based materials have been used as organic scaffolds for biomineralization of hydroxyapatite [98, 99], silver [100], silica [96, 101-103], and titanium [104]. 
Detailed control of silica morphology and distribution on the surface of the silk films was achieved by fusing $N$. clavipies dragline sequences and the silaffin-derived R5 peptide of the diatom (Cylindrotheca fusiformis) [96, 101, 102, 105]. Three-dimensional porous networks were formed with clustered silica nanoparticles and single silica nanoparticles on the surface of chimeric spider silk films. The silk served as the organic scaffolding to control material stability. The silk/silica biomaterials are suitable for different tissue regenerative applications. For example, human bone marrow derived mesenchymal stem cells subjected to osteogenic differentiation were used to evaluate the influence of the silk-silica composite systems on osteogenesis [106]. The silica in these silk films influenced osteogenic gene expression, with upregulation of several osteogenic markers (i.e., alkaline phosphatase, bone sialoprotein, and collagen type I). Furthermore, calcium containing deposits were observed on silk films treated with silica as a strong indication of bone formation [105]. Benton et al. (2012) investigated the influence of the silk/chimera ratio through the adjustment of the type and number of silicifying domains) together with the effect of $\mathrm{pH}(3-9)$ on reactivity. The driving force for fast silicification was likely the water reduced environment of spider silk protein domains, making the removal of water from the silica condensation reactions energetically more favorable and resulting in the rapid formation of large silica particles ( $800 \mathrm{~nm}$ and $2 \mu \mathrm{m}$, dispersity of $\pm 10 \%$ ) in the presence of the silk fusion proteins [103].

Recently, Currie at el. reported the production of new recombinant silk-silver binding chimeric proteins capable of forming silver nanostructures from a $\mathrm{AgNO}_{3}$ solution on silk films [100]. Two silver binding peptides, Ag-4(NPSSLFRYLPSD) and AgP35(WSWRSPTPHVVT), were previously identified by phage display [107]. The peptides were fused with recombinant spider silk 6-mer and 15-mer proteins originated from MaSp1 of $N$. clavipes. The formation of silver nanostructures (nanoparticles and nano-rods) from a silver nitrate solution was observed with the average particle size of $35.5 \mathrm{~nm} \pm 8.5 \mathrm{~nm}$, average rod diameter of $57.2 \mathrm{~nm} \pm 17 \mathrm{~nm}$ and length $226 \mathrm{~nm} \pm 82 \mathrm{~nm}$ for 6-mer Ag-4 and 15-mer Ag-4, respectively. The antimicrobial capacity of the silver treated protein films was also examined by incubation with both Gram-positive and Gram-negative bacteria. The silver treated silk films significantly inhibited the growth of both bacterial species. The incorporation of an inorganic phase through mineralization of a silk based substrate establishes new materials which incorporate the mechanical strength, biocompatibility and aqueous processing of silk with added functions due to the chimeric mineralizing domains encoded in the new bioengineered proteins. In a different approach, silk fibroins from $B$. mori were chemically grafted with titanium binding peptide to increase adsorption of these chimeric proteins to metal surfaces [104], indicating utility for new composite materials.

Spider dragline silk of $N$. clavipes was fused with a hydroxyapatite binding peptide from dentin matrix protein I (DMP1) via a genetic approach [99]. Calcium hydroxyapatite (HA), $\mathrm{Ca}_{10}\left(\mathrm{PO}_{4}\right)_{6}(\mathrm{OH})_{2}$, is central in bone and dentin formation. Both collagenous macromolecules and non-collagenous proteins such as phosphoproteins, osteonectin and dentin matrix protein I are involved in controlling the nucleation and growth of HA crystals in these tissues. DMP1 has two acidic domains ESQES (residues 386-390) and QESQSEQDS (residues 414-422) that control $\mathrm{Ca}^{2+}$ binding and play a critical role in HA nucleation [108]. The resulting silk-DMP1 chimeric protein demonstrated successful nucleation of HA crystals on the surface of silk films confirmed by FESEM coupled with energy dispersive X-ray spectroscopy.

A different approach was taken by Lee and coworkers (2009), where multiple pulsed vaporphase infiltration was used to improve the mechanical properties of spider dragline silks by direct metal incorporation into inner regions of the protein fiber structures. The result was the formation of a metal-incorporated protein matrix. The authors demonstrated that metals can be intentionally infiltrated through multiple pulsed vapor-phase processes performed 
with equipment conventionally used for atomic layer deposition. Pulsed vapor-phase incorporation of zinc, titanium and aluminum into spider dragline silks increased the strength and toughness of the material [109].

\section{Future Outlook}

The majority of knowledge about structure-function relationships in spider silks comes from three types of spider silk proteins: major ampullate spidroins, minor ampullate spidroins, and flagelliform silks. It has been possible to relate protein sequences to molecular structures and to the physical properties of native fibers. Currently much effort has been made to unravel the features of other types of silk such as aciniform, tubuliform, and pyriform. In addition, the majority of work has been focused on orb-weaving spiders. Hence, it is necessary to broaden attention to other types of spiders (e.g. cob-weaving spiders), and other members of the class Arachnida. A recent discovery of a novel silk system in the tubebuilding corophioid amphipod Crassicorophium bonellii is an example of these possibilities [110]. Natural silks have potential for a variety of material science and biomedical applications[111]. Over the last decade there has been considerable progress in understanding the genetic organization encoding spider silks. Cloning and expression for spider silk genes have improved, and the self-assembly and processing of spider silk into many material formats is now better understood. Just recently a native-sized ( $285 \mathrm{kDa})$ recombinant protein of the spider Nephila clavipes was produced and spun into a fiber displaying mechanical properties comparable to those of the native silk, indicating a breakthrough in standard recombinant production of spider silks [112]. Moreover, transgenic silkworm/spider silk production systems have been developed to produce tough fibers. It is possible to mix and match key modules via recombinant approaches, providing additional insights into the role of individual modules and effects of neighboring elements on properties. This approach should lead to the development of custom structures built from specific silk elements. Future challenges will include scaling up silk production. In addition molecular-level analysis of the nanostructure of silk assemblies using in silico approaches should play an important role to understand structure-property-function relationships.

\section{Acknowledgments}

The authors thank the NIH (EB014976, EB002520; EY020856; DE017207; EB014283) for support of the studies reviewed here.

\section{References}

1. Hu X, Vasanthavada K, Kohler K, McNary S, Moore A, Vierra C. Molecular mechanisms of spider silk. Cellular and Molecular Life Sciences. 2006; 63:1986-99. [PubMed: 16819558]

2. Breslauer, DN.; Kaplan, DL. 9.04 - Silks. In: Krzysztof, M.; Martin, M., editors. Polymer Science: A Comprehensive Reference. Amsterdam: Elsevier; 2012. p. 57-69.

3. Eisoldt L, Smith A, Scheibel T. Decoding the secrets of spider silk. Materials Today. 2011; 14:80-6.

4. Vollrath F. Spider silk: thousands of nano-filaments and dollops of sticky glue. Current Biology. 2006; 16:925-7.

5. Gosline J, Guerette P, Ortlepp C, Savage K. The mechanical design of spider silks: from fibroin sequence to mechanical function. J Exp Biol. 1999; 202:3295-303. [PubMed: 10562512]

6. Humenik M, Scheibel T, Smith A. Spider silk understanding the structure-function relationship of a natural fiber. Prog Mol Biol Transl Sci. 2011; 103:131-85. [PubMed: 21999996]

7. Gosline JM, Denny MW, DeMont ME. Spider silk as rubber. Nature. 1984; 309:551-2.

8. Vepari C, Kaplan DL. Silk as a biomaterial. Progress in Polymer Science. 2007; 32:991-1007. [PubMed: 19543442] 
9. Heim M, Keerl D, Scheibel T. Spider silk: from soluble protein to extraordinary eiber. Angewandte Chemie International Edition. 2009; 48:3584-96.

10. Blackledge TA, Summers AP, Hayashi CY. Gumfooted lines in black widow cobwebs and the mechanical properties of spider capture silk. Zoology. 2005; 108:41-6. [PubMed: 16351953]

11. Shear WA, Palmer JM, Coddington JA, Bonamo PM. A Devonian Spinneret: Early Evidence of Spiders and Silk Use. Science. 1989; 246:479-81. [PubMed: 17788699]

12. Lewis RV. Spider silk: ancient ideas for new biomaterials. Chem Rev. 2006; 106:3762-74. [PubMed: 16967919]

13. Asakura T, Umemura K, Nakazawa Y, Hirose H, Higham J, Knight D. Some observations on the structure and function of the spinning apparatus in the silkworm Bombyx mori.

Biomacromolecules. 2007; 8:175-81. [PubMed: 17206804]

14. Teulé F, Addison B, Cooper AR, Ayon J, Henning RW, Benmore CJ, et al. Combining flagelliform and dragline spider silk motifs to produce tunable synthetic biopolymer fibers. Biopolymers. 2012; 97:418-31. [PubMed: 22012252]

15. Lewicka M, Hermanson O, Rising AU. Recombinant spider silk matrices for neural stem cell cultures. Biomaterials. 2012; 33:7712-7. [PubMed: 22863380]

16. Vollrath F, Porter D. Silks as ancient models for modern polymers. Polymer. 2009; 50:5623-32.

17. Sponner A. Spider silk as a resource for future biotechnologies. Entomological Research. 2007; 37:238-50.

18. Blackledge TA. Spider silk: A brief review and prospectus on research linking biomechanics and ecology in draglines and orb webs. Journal of Arachnology. 2012; 40:1-12.

19. The Genetics of Cancer. London: Academic Press; 1997. References; p. 215-326.

20. Vollrath F, Knight DP. Liquid crystalline spinning of spider silk. Nature. 2001; 410:541-8. [PubMed: 11279484]

21. Lewis R. Spider silk production. Bionanotechnology. 2006:61-78.

22. Rising A, Nimmervoll H, Grip S, Fernandez-Arias A, Storckenfeldt E, Knight DP, et al. Spider silk proteins - Mechanical property and gene sequence. Zoological Science. 2005; 22:273-81. [PubMed: 15795489]

23. Vollrath F, Knight DP. Structure and function of the silk production pathway in the spider Nephila edulis. International Journal of Biological Macromolecules. 1999; 24:243-9. [PubMed: 10342771]

24. Knight DP, Knight MM, Vollrath F. Beta transition and stress-induced phase separation in the spinning of spider dragline silk. International Journal of Biological Macromolecules. 2000; 27:205-10. [PubMed: 10828366]

25. Rising A, Hjalm G, Engstrom W, Johansson J. N-Terminal Nonrepetitive Domain Common to Dragline, Flagelliform, and Cylindriform Spider Silk Proteins. Biomacromolecules. 2006; 7:3120_ 4. [PubMed: 17096540]

26. Knight DP, Vollrath F. Changes in element composition along the spinning duct in a Nephila spider. Naturwissenschaften. 2001; 88:179-82. [PubMed: 11480706]

27. Xu M, Lewis R. Structure of a Protein Superfiber: Spider Dragline Silk 10.1073/pnas.87.18. 7120. Proceedings of the National Academy of Sciences. 1990; 87:7120-4.

28. Hayashi CY, Shipley NH, Lewis RV. Hypotheses that correlate the sequence, structure, and mechanical properties of spider silk proteins. International Journal of Biological Macromolecules. 1999; 24:271-5. [PubMed: 10342774]

29. Brooks AE, Steinkraus HB, Nelson SR, Lewis RV. An investigation of the divergence of major ampullate silk fibers from Nephila clavipes and Argiope aurantia. Biomacromolecules. 2005; 6:3095-9. [PubMed: 16283732]

30. Huemmerich D, Helsen CW, Quedzuweit S, Oschmann J, Rudolph R, Scheibel T. Primary structure elements of spider dragline silks and their contribution to protein solubility. Biochemistry. 2004; 43:13604-12. [PubMed: 15491167]

31. Ayoub NA, Garb JE, Tinghitella RM, Collin MA, Hayashi CY. Blueprint for a High-Performance Biomaterial: Full-Length Spider Dragline Silk Genes. PLoS ONE. 2007; 2:e514. [PubMed: 17565367] 
32. Ittah S, Cohen S, Garty S, Cohn D, Gat U. An essential role for the C-terminal domain of a dragline spider silk protein in directing fiber formation. Biomacromolecules. 2006; 7:1790-5. [PubMed: 16768399]

33. Chen G, Liu X, Zhang Y, Lin S, Yang Z, Johansson J, et al. Full-Length Minor Ampullate Spidroin Gene Sequence. PLoS ONE. 2012; 7:e52293. [PubMed: 23251707]

34. Holland GP, Jenkins JE, Creager MS, Lewis RV, Yarger JL. Solid-state NMR investigation of major and minor ampullate spider silk in the native and hydrated states. Biomacromolecules. 2008; 9:651-7. [PubMed: 18171016]

35. Colgin MA, Lewis RV. Spider minor ampullate silk proteins contain new repetitive sequences and highly conserved non-silk-like "spacer regions". Protein Sci. 1998; 7:667-72. [PubMed: 9541398]

36. Hayashi CY, Lewis RV. Evidence from flagelliform silk cDNA for the structural basis of elasticity and modular nature of spider silks. Journal of Molecular Biology. 1998; 275:773-84. [PubMed: 9480768]

37. Hayashi CY, Lewis RV. Spider flagelliform silk: lessons in protein design, gene structure, and molecular evolution. BioEssays. 2001; 23:750-6. [PubMed: 11494324]

38. Becker N, Oroudjev E, Mutz S, Cleveland JP, Hansma PK, Hayashi CY, et al. Molecular nanosprings in spider capture-silk threads. Nature Materials. 2003; 2:278-83.

39. Hayashi CY, Blackledge TA, Lewis RV. Molecular and mechanical characterization of aciniform silk: Uniformity of iterated sequence modules in a novel member of the spider silk fibroin gene family. Molecular Biology and Evolution. 2004; 21:1950-9. [PubMed: 15240839]

40. Hu X, Lawrence B, Kohler K, Falick AM, Moore AMF, McMullen E, et al. Araneoid egg case silk: A fibroin with novel ensemble repeat units from the black widow spider, Latrodectus hesperus. Biochemistry. 2005; 44:10020-7. [PubMed: 16042378]

41. Van Nimmen E, Gellynck K, Gheysens T, Van Langenhove L, Mertens J. MODELING OF THE STRESS-STRAIN BEHAVIOR OF EGG SAC SILK OF THE SPIDER ARANEUS DIADEMATUS. Journal of Arachnology. 2005:629-39.

42. Tian M, Lewis RV. Tubuliform silk protein: A protein with unique molecular characteristics and mechanical properties in the spider silk fibroin family. Applied Physics A: Materials Science \& Processing. 2006; 82:265-73.

43. Hu X, Kohler K, Falick AM, Moore AMF, Jones PR, Vierra C. Spider Egg Case Core Fibers: Trimeric Complexes Assembled from TuSp1, ECP-1, and ECP-2†. Biochemistry. 2006; 45:350616. [PubMed: 16533031]

44. Hu X, Yuan J, Wang X, Vasanthavada K, Falick AM, Jones PR, et al. Analysis of Aqueous Glue Coating Proteins on the Silk Fibers of the Cob Weaver, Latrodectus hesperus $\dagger$. Biochemistry. 2007; 46:3294-303. [PubMed: 17311422]

45. Craig, Vierra; Yang, Hsia; Eric, Gnesa; Simon, Tang; Felicia, J. Spider Silk Composites and Applications. In: Cuppoletti, J., editor. Metal, Ceramic and Polymeric Composites for Various Uses. InTech; 2011.

46. Blasingame E, Tuton-Blasingame T, Larkin L, Falick AM, Zhao L, Fong J, et al. Pyriform spidroin 1 , a novel member of the silk gene family that anchors dragline silk fibers in attachment discs of the black widow spider, Latrodectus hesperus. J Biol Chem. 2009; 284:29097-108. [PubMed: 19666476]

47. Vasanthavada K, Hu X, Tuton-Blasingame T, Hsia Y, Sampath S, Pacheco R, et al. Spider glue proteins have distinct architectures compared with traditional spidroin family members. J Biol Chem. 2012; 287:35986-99. [PubMed: 22927444]

48. Perry DJ, Bittencourt D, Siltberg-Liberles J, Rech EL, Lewis RV. Piriform Spider Silk Sequences Reveal Unique Repetitive Elements. Biomacromolecules. 2010; 11:3000-6. [PubMed: 20954740]

49. Blasingame E, Tuton-Blasingame T, Larkin L, Falick AM, Zhao L, Fong J, et al. Pyriform Spidroin 1, a Novel Member of the Silk Gene Family That Anchors Dragline Silk Fibers in Attachment Discs of the Black Widow Spider, Latrodectus hesperus. Journal of Biological Chemistry. 2009; 284:29097-108. [PubMed: 19666476]

50. Geurts P, Zhao L, Hsia Y, Gnesa E, Tang S, Jeffery F, et al. Synthetic Spider Silk Fibers Spun from Pyriform Spidroin 2, A Glue Silk Protein Discovered in Orb-Weaving Spider Attachment Discs $\dagger$. Biomacromolecules. 2010; 11:3495-503. [PubMed: 21053953] 
51. Hedhammar M, Rising A, Grip S, Martinez AS, Nordling K, Casals C, et al. Structural properties of recombinant nonrepetitive and repetitive parts of major ampullate spidroin 1 from Euprosthenops australis: Implications for fiber formation. Biochemistry. 2008; 47:3407-17. [PubMed: 18293938]

52. Rising A, Widhe M, Johansson J, Hedhammar M. Spider silk proteins: recent advances in recombinant production, structure-function relationships and biomedical applications. Cell Mol Life Sci. 2011; 68:169-84. [PubMed: 20668909]

53. Esipova NG, Ragulina LE, Davydova LI, Lobachev VM, Makeev VY, Bogush VG, et al. Left helix of polyproline II type and genesis of $\beta$-structures in spidroins 1 and 2 and their recombinant analogs. BIOPHYSICS. 2009; 54:271-4.

54. Holland C, Terry AE, Porter D, Vollrath F. Natural and unnatural silks. Polymer. 2007; 48:338892.

55. Jenkins JE, Holland GP, Yarger JL. High resolution magic angle spinning NMR investigation of silk protein structure within major ampullate glands of orb weaving spiders. Soft Matter. 2012; 8:1947-54.

56. Guan J, Vollrath F, Porter D. Two Mechanisms for Supercontraction in Nephila Spider Dragline Silk. Biomacromolecules. 2011; 12:4030-5. [PubMed: 21951163]

57. Bratzel G, Buehler MJ. Sequence-structure correlations in silk: Poly-Ala repeat of N. clavipes MaSp1 is naturally optimized at a critical length scale. Journal of the Mechanical Behavior of Biomedical Materials. 2012; 7:30-40. [PubMed: 22340682]

58. Kummerlen J, Van Beek JD, Vollrath F, Meier BH. Local structure in spider dragline silk investigated by two-dimensional spin-diffusion nuclear magnetic resonance. Macromolecules. 1996; 29:2920-8.

59. Kluge JA, Rabotyagova O, Leisk GG, Kaplan DL. Spider silks and their applications. Trends in Biotechnology. 2008; 26:244-51. [PubMed: 18367277]

60. Vendrely, C.; Ackerschott, C.; Römer, L.; Scheibel, T. Molecular design of performance proteins with repetitive sequences: Recombinant flagelliform spider silk as basis for biomaterials. Gazit, E.; Nussinov, R., editors. 2008. p. 3-14.

61. Hinman MB, Jones JA, Lewis RV. Synthetic spider silk: a modular fiber. Trends in Biotechnology. 2000; 18:374-9. [PubMed: 10942961]

62. Savage KN, Gosline JM. The role of proline in the elastic mechanism of hydrated spider silks. Journal of Experimental Biology. 2008; 211:1948-57. [PubMed: 18515725]

63. Lewis, R. Sequences, Structures, and Properties of Spider Silk. In: Shewry, PR.; Tatham, AS.; Bailey, AJ., editors. Elastomeric Proteins: Structures, Biomechanical Properties, and Biological Roles. Cambridge: Cambridge University Press; 2004. p. 408

64. Xiao S, Stacklies W, Cetinkaya M, Markert B, Grater F. Mechanical response of silk crystalline units from force-distribution analysis. Biophysical Journal. 2009; 96:3997-4005. [PubMed: 19450471]

65. Um IC, Ki CS, Kweon H, Lee KG, Ihm DW, Park YH. Wet spinning of silk polymer. II. Effect of drawing on the structural characteristics and properties of filament. International Journal of Biological Macromolecules. 2004; 34:107-19. [PubMed: 15178015]

66. Teule F, Cooper AR, Furin WA, Bittencourt D, Rech EL, Brooks A, et al. A protocol for the production of recombinant spider silk-like proteins for artificial fiber spinning. Nat Protoc. 2009; 4:341-55. [PubMed: 19229199]

67. Breslauer DN, Lee LP, Muller SJ. Simulation of flow in the silk gland. Biomacromolecules. 2009; 10:49-57. [PubMed: 19053289]

68. Lazaris A, Arcidiacono S, Huang Y, Zhou JF, Duguay F, Chretien N, et al. Spider silk fibers spun from soluble recombinant silk produced in mammalian cells. Science. 2002; 295:472-6. [PubMed: 11799236]

69. Chen X, Cai H, Ling S, Shao Z, Huang Y. Conformation transition of Bombyx mori silk protein monitored by time-dependent fourier transform infrared (FT-IR) spectroscopy: effect of organic solvent. Appl Spectrosc. 2012; 66:696-9. [PubMed: 22732542] 
70. An B, Hinman MB, Holland GP, Yarger JL, Lewis RV. Inducing beta-sheets formation in synthetic spider silk fibers by aqueous post-spin stretching. Biomacromolecules. 2011; 12:237581. [PubMed: 21574576]

71. Gronau G, Krishnaji ST, Kinahan ME, Giesa T, Wong JY, Kaplan DL, et al. A review of combined experimental and computational procedures for assessing biopolymer structure-process-property relationships. Biomaterials. 2012; 33:8240-55. [PubMed: 22938765]

72. Bratzel G, Buehler MJ. Molecular mechanics of silk nanostructures under varied mechanical loading. Biopolymers. 2012; 97:408-17. [PubMed: 22020792]

73. Jin HJ, Fridrikh SV, Rutledge GC, Kaplan DL. Electrospinning Bombyx mori silk with poly(ethylene oxide). Biomacromolecules. 2002; 3:1233-9. [PubMed: 12425660]

74. Pan H, Zhang Y, Hang Y, Shao H, Hu X, Xu Y, et al. Significantly reinforced composite fibers electrospun from silk fibroin/carbon nanotube aqueous solutions. Biomacromolecules. 2012; 13:2859-67. [PubMed: 22881188]

75. Gui-Bo Y, You-Zhu Z, Shu-Dong W, De-Bing S, Zhi-Hui D, Wei-Guo F. Study of the electrospun PLA/silk fibroin-gelatin composite nanofibrous scaffold for tissue engineering. J Biomed Mater Res A. 2010; 93:158-63. [PubMed: 19536837]

76. Wang CY, Zhang KH, Fan CY, Mo XM, Ruan HJ, Li FF. Aligned natural-synthetic polyblend nanofibers for peripheral nerve regeneration. Acta Biomaterialia. 2011; 7:634-43. [PubMed: 20849984]

77. Wittmer CR, Claudepierre T, Reber M, Wiedemann P, Garlick JA, Kaplan D, et al. Multifunctionalized electrospun silk fibers promote axon regeneration in central nervous system. Adv Funct Mater. 2011; 21:4202. [PubMed: 22844266]

78. Liu H, Li X, Zhou G, Fan H, Fan Y. Electrospun sulfated silk fibroin nanofibrous scaffolds for vascular tissue engineering. Biomaterials. 2011; 32:3784-93. [PubMed: 21376391]

79. Sheng X, Fan L, He C, Zhang K, Mo X, Wang H. Vitamin E-loaded silk fibroin nanofibrous mats fabricated by green process for skin care application. International Journal of Biological Macromolecules. 2013; 56C:49-56. [PubMed: 23396066]

80. Li C, Vepari C, Jin HJ, Kim HJ, Kaplan DL. Electrospun silk-BMP-2 scaffolds for bone tissue engineering. Biomaterials. 2006; 27:3115-24. [PubMed: 16458961]

81. Rabotyagova OS, Cebe P, Kaplan DL. Protein-based block copolymers. Biomacromolecules. 2011; 12:269-89. [PubMed: 21235251]

82. Hamley, IW. Block Copolymers in Solution: Fundamentals and Applications. Chichester: Wiley and Sons, Ltd; 2005.

83. Rabotyagova OS, Cebe P, Kaplan DL. Self-assembly of genetically engineered spider silk block copolymers. Biomacromolecules. 2009; 10:229-36. [PubMed: 19128057]

84. Rabotyagova OS, Cebe P, Kaplan DL. Role of polyalanine Domains in beta-sheet formation in spider silk block copolymers. Macromolecular Bioscience. 2010; 10:49-59. [PubMed: 19890885]

85. Huang W, Krishnaji S, Hu X, Kaplan D, Cebe P. Heat Capacity of Spider Silk-Like Block Copolymers. Macromolecules. 2011; 44:5299-309. [PubMed: 23869111]

86. Krishnaji ST, Huang W, Rabotyagova O, Kharlampieva E, Choi I, Tsukruk VV, et al. Thin film assembly of spider silk-like block copolymers. Langmuir. 2011; 27:1000-8. [PubMed: 21207952]

87. Werten MWT, Moers APHA, Vong T, Zuilhof H, van Hest JCM, de Wolf FA. Biosynthesis of an Amphiphilic Silk-Like Polymer. Biomacromolecules. 2008; 9:1705-11. [PubMed: 18517247]

88. Krejchi MT, Atkins EDT, Waddon AJ, Fournier MJ, Mason TL, Tirrel DA. Chemical sequence control of beta-sheet assembly in macromolecular crystals of periodic polypeptides. Science. 1994; 265:1427-32. [PubMed: 8073284]

89. Qu Y, Payne SC, Apkarian RP, Conticello VP. Self-Assembly of a Polypeptide Multi-Block Copolymer Modeled on Dragline Silk Proteins. J Am Chem Soc. 2000; 122:5014-5.

90. Higashiya S, Topilina NI, Ngo SC, Zagorevskii D, Welch JT. Design and Preparation of b-Sheet Forming Repetitive and Block-Copolymerized Polypeptides. Biomacromolecules. 2007; 8:148797. [PubMed: 17388563]

91. Hardy JG, Scheibel TR. Composite materials based on silk proteins. Progress in Polymer Science. 2010; 35:1093-115. 
92. Spiess K, Lammel A, Scheibel T. Recombinant Spider Silk Proteins for Applications in Biomaterials. Macromolecular Bioscience. 2010; 10:998-1007. [PubMed: 20602494]

93. An B, Jenkins JE, Sampath S, Holland GP, Hinman M, Yarger JL, et al. Reproducing natural spider silks' copolymer behavior in synthetic silk mimics. Biomacromolecules. 2012; 13:3938-48. [PubMed: 23110450]

94. Teulé F, Miao Y-G, Sohn B-H, Kim Y-S, Hull JJ, Fraser MJ, et al. Silkworms transformed with chimeric silkworm/spider silk genes spin composite silk fibers with improved mechanical properties. Proceedings of the National Academy of Sciences. 2012

95. Kojima K, Kuwana Y, Sezutsu H, Kobayashi I, Uchino K, Tamura T, et al. A new method for the modification of fibroin heavy chain protein in the transgenic silkworm. Bioscience, Biotechnology, and Biochemistry. 2007; 71:2943-51.

96. Wang C, Patwardhan SV, Belton DJ, Kitchel B, Anastasiades D, Huang J, et al. Novel nanocomposites from spider silk-silica fusion (chimeric) proteins. Proceedings of the National Academy of Sciences of the United States of America. 2006; 103:9428-33. [PubMed: 16769898]

97. Otzen D. The Role of Proteins in Biosilicification. Scientifica. 2012; 2012:22.

98. Cao B, Mao C. Oriented nucleation of hydroxylapatite crystals on spider dragline silks. Langmuir. 2007; 23:10701-5. [PubMed: 17850102]

99. Huang J, Wong C, George A, Kaplan DL. The effect of genetically engineered spider silk-dentin matrix protein 1 chimeric protein on hydroxyapatite nucleation. Biomaterials. 2007; 28:2358-67. [PubMed: 17289141]

100. Currie HA, Deschaume O, Naik RR, Perry CC, Kaplan DL. Genetically Engineered Chimeric Silk-Silver Binding Proteins. Advanced Functional Materials. 2011; 21:2889-95. [PubMed: 23795153]

101. Mieszawska AJ, Nadkarni LD, Perry CC, Kaplan DL. Nanoscale Control of Silica Particle Formation via Silk Silica Fusion Proteins for Bone Regeneration. Chemistry of Materials. 2010; 22:5780-5. [PubMed: 20976116]

102. Canabady-Rochelle LLS, Belton DJ, Deschaume O, Currie HA, Kaplan DL, Perry CC. Bioinspired silicification of silica-binding peptide-silk protein chimeras: Comparison of chemically and genetically produced proteins. Biomacromolecules. 2012; 13:683-90. [PubMed: 22229696]

103. Belton DJ, Mieszawska AJ, Currie HA, Kaplan DL, Perry CC. Silk-silica composites from genetically engineered chimeric proteins: Materials properties correlate with silica condensation rate and colloidal stability of the proteins in aqueous solution. Langmuir. 2012; 28:4373-81. [PubMed: 22313382]

104. Vidal G, Blanchi T, Mieszawska AJ, Calabrese R, Rossi C, Vigneron P, et al. Enhanced cellular adhesion on titanium by silk functionalized with titanium binding and RGD peptides. Acta Biomaterialia. 2013; 9:4935-43. [PubMed: 22975628]

105. Mieszawska AJ, Fourligas N, Georgakoudi I, Ouhib NM, Belton DJ, Perry CC, et al. Osteoinductive silk-silica composite biomaterials for bone regeneration. Biomaterials. 2010; 31:8902-10. [PubMed: 20817293]

106. Mieszawska AJ, Fourligas N, Georgakoudi I, Ouhib NM, Belton DJ, Perry CC, et al. Osteoinductive silk-silica composite biomaterials for bone regeneration. Biomaterials. 2010; 31:8902-10. [PubMed: 20817293]

107. Naik RR, Jones SE, Murray CJ, McAuliffe JC, Vaia RA, Stone MO. Peptide Templates for Nanoparticle Synthesis Derived from Polymerase Chain Reaction-Driven Phage Display. Advanced Functional Materials. 2004; 14:25-30.

108. He G, George A. Dentin Matrix Protein 1 Immobilized on Type I Collagen Fibrils Facilitates Apatite Deposition in Vitro. Journal of Biological Chemistry. 2004; 279:11649-56. [PubMed: 14699165]

109. Lee SM, Pippel E, Gösele U, Dresbach C, Qin Y, Chandran CV, et al. Greatly increased toughness of infiltrated spider silk. Science. 2009; 324:488-92. [PubMed: 19390040]

110. Kronenberger K, Dicko C, Vollrath F. A novel marine silk. Naturwissenschaften. 2012; 99:3-10. [PubMed: 22057952] 
111. Wang Y, Blasioli DJ, Kim H-J, Kim HS, Kaplan DL. Cartilage tissue engineering with silk scaffolds and human articular chondrocytes. Biomaterials. 2006; 27:4434-42. [PubMed: 16677707]

112. Xia X-X, Qian Z-G, Ki CS, Park YH, Kaplan DL, Lee SY. Native-sized recombinant spider silk protein produced in metabolically engineered Escherichia coli results in a strong fiber. Proceedings of the National Academy of Sciences. 2010; 107:14059-63.

113. Kojic N, Bico J, Clasen C, McKinley GH. Ex vivo rheology of spider silk. J Exp Biol. 2006; 209:4355-62. [PubMed: 17050850]

114. Vollrath F. Strength and structure of spiders' silks. J Biotechnol. 2000; 74:67-83. [PubMed: 11763504]

115. Guinea GV, Elices M, Plaza GR, Perea GB, Daza R, Riekel C, et al. Minor Ampullate Silks from Nephila and Argiope Spiders: Tensile Properties and Microstructural Characterization. Biomacromolecules. 2012; 13:2087-98. [PubMed: 22668322]

116. Teule F, Cooper AR, Furin WA, Bittencourt D, Rech EL, Brooks A, et al. A protocol for the production of recombinant spider silk-like proteins for artificial fiber spinning. Nat Protocols. 2009; 4:341-55. 

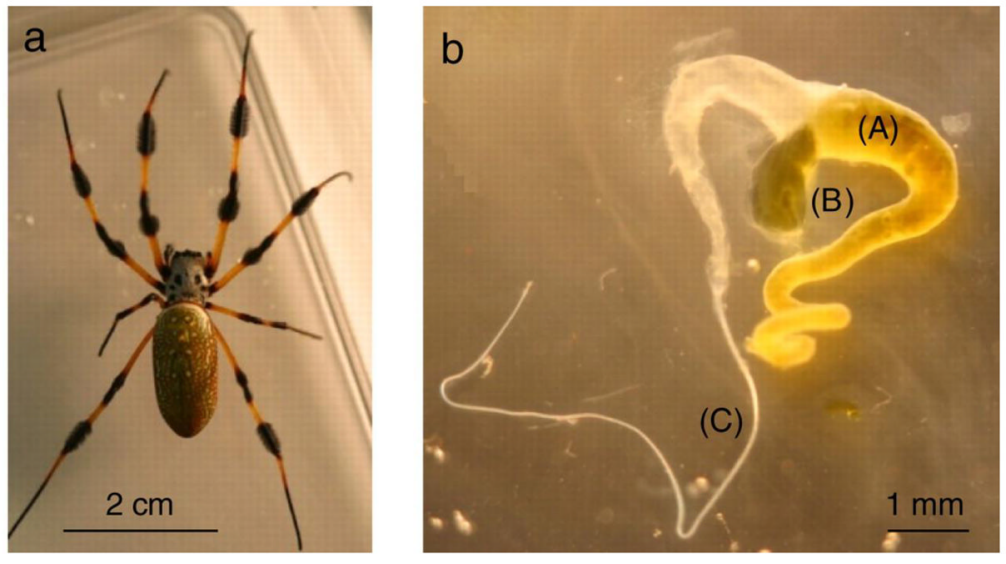

Figure 1.

(a) Adult female Nephila Clavipes (golden-orb) spider provided by the Miami Metrozoo, Florida. (b) (A) Dissected major ampullate (MA) gland of the spider. The $\sim 1 \mu \mathrm{l}$ blob (B) protruding through a rupture of the gland wall near the spinning canal $(\mathrm{C})$ was used for the rheology experiments. Modified with permission from [113]. 
(a)

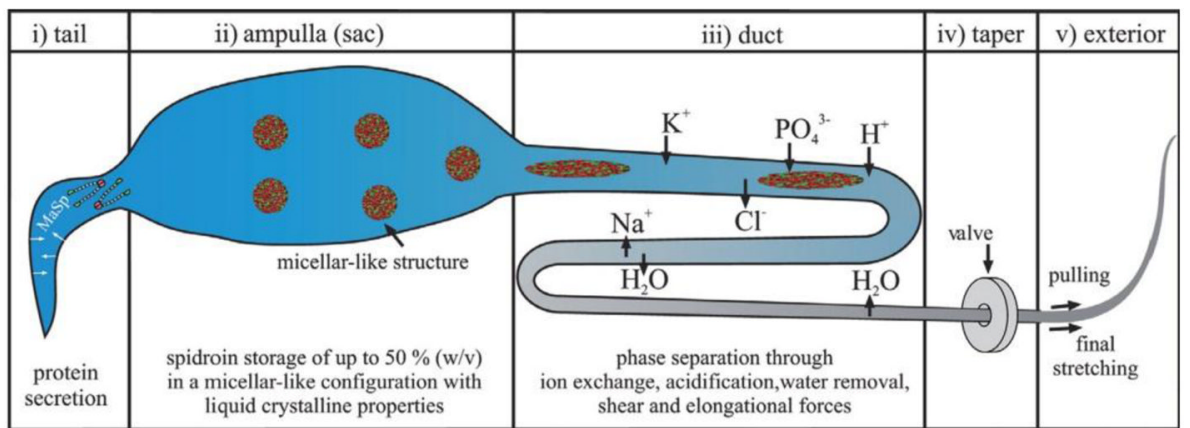

(b)

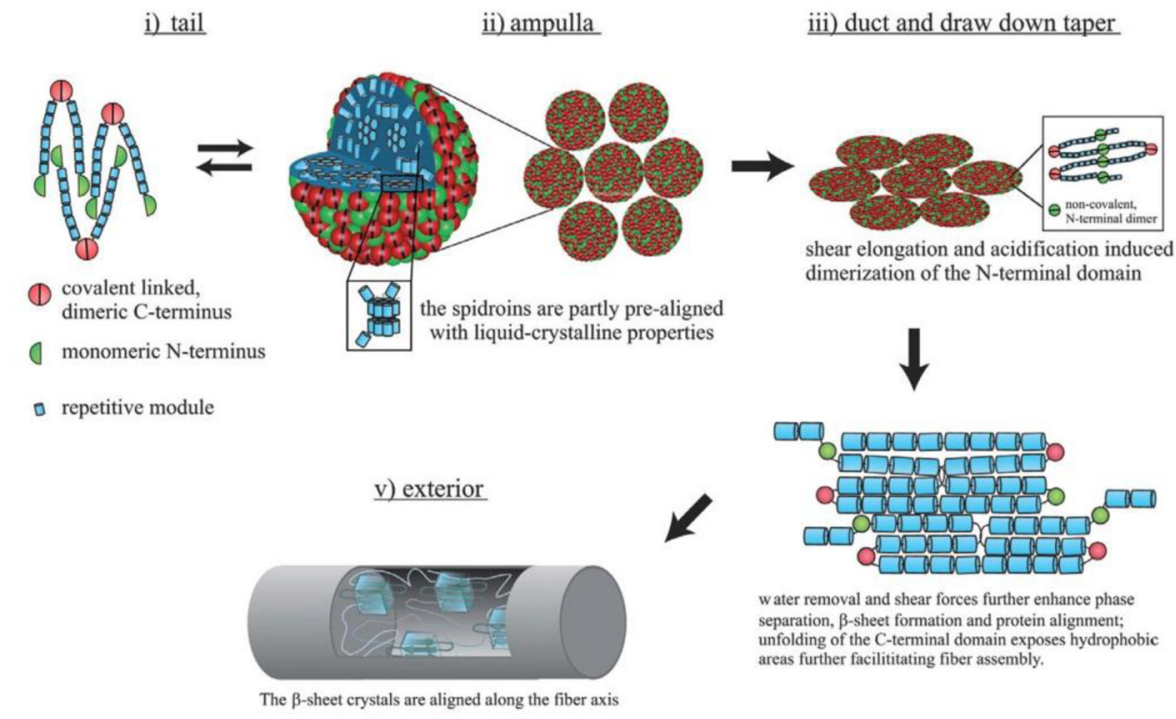

Figure 2.

The natural spinning process. (a) Illustration of a spider's spinning gland divided into four parts. (b) Schematic model of the silk fiber assembly mechanism occurring along the spinning apparatus. Reproduced with permission from [3]. 


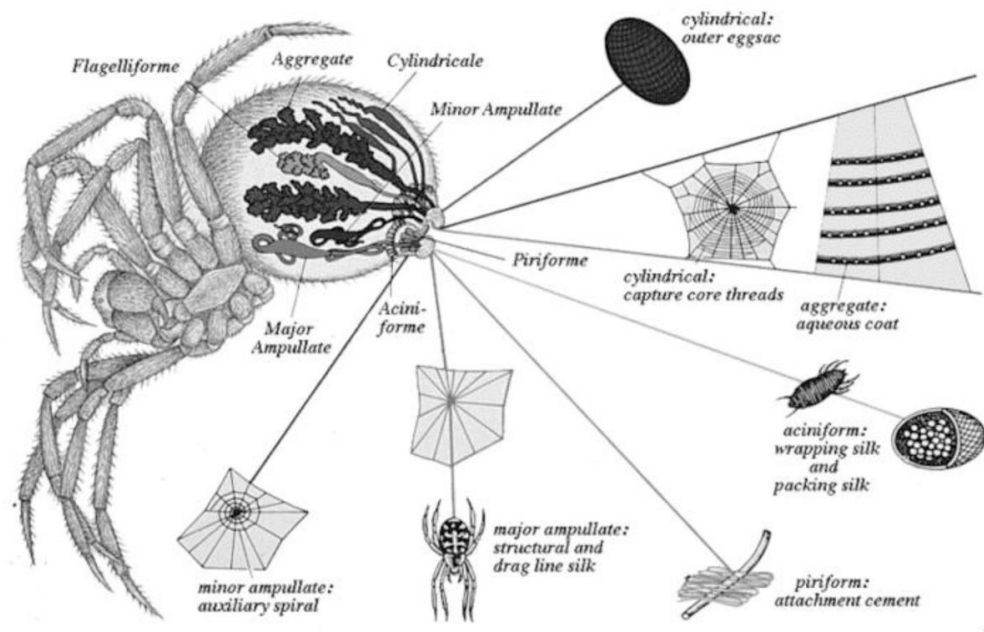

Figure 3.

Silk glands, silk types and silk uses of Nephila clavipes. Reproduced with permission from [114]. 


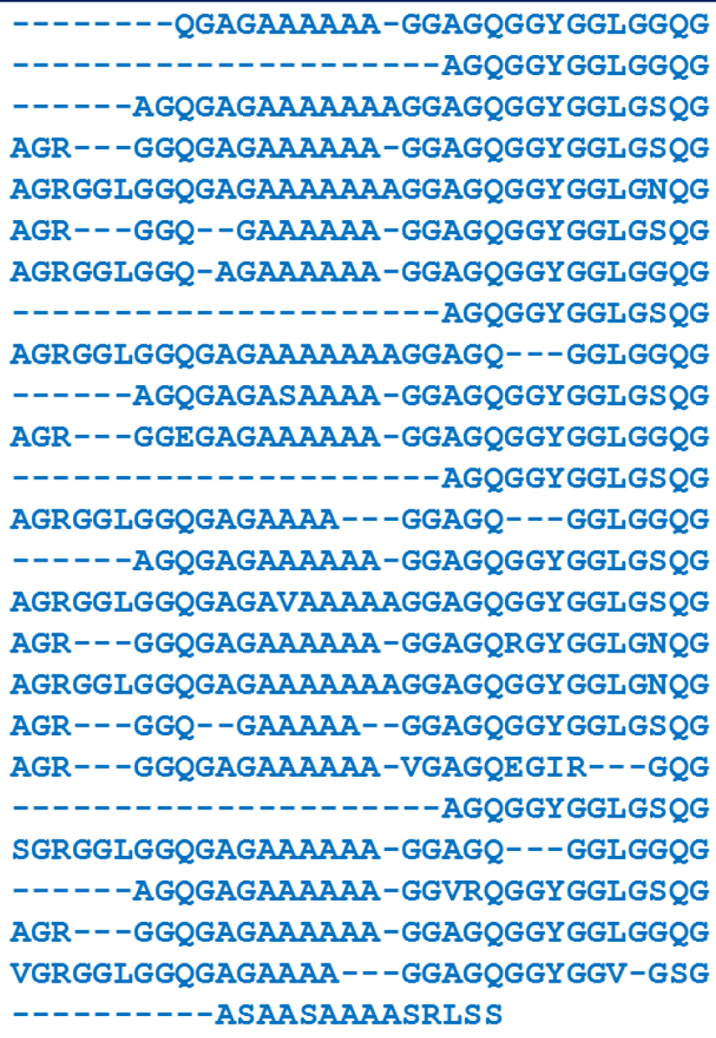

Figure 4. Nephila clavipes

MaSp1 repeating units. Reproduced with permission and adapted from [27]. 


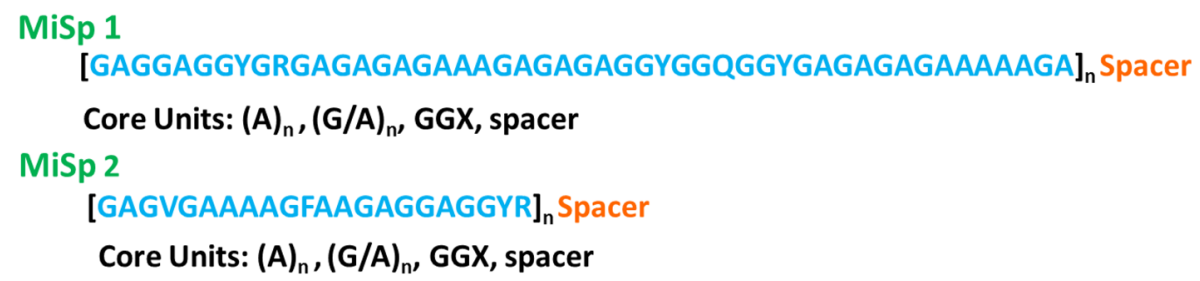

Figure 5.

Consensus amino acid sequence of minor ampullate silk protein 1 and 2 from $N$. clavipes. Adapted with permission from [115] and GenBank accession no. AAC14589. 


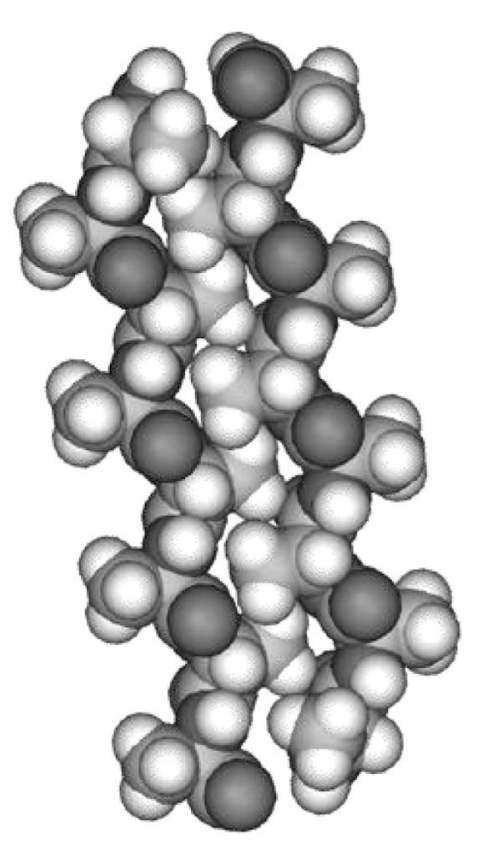

Poly ala

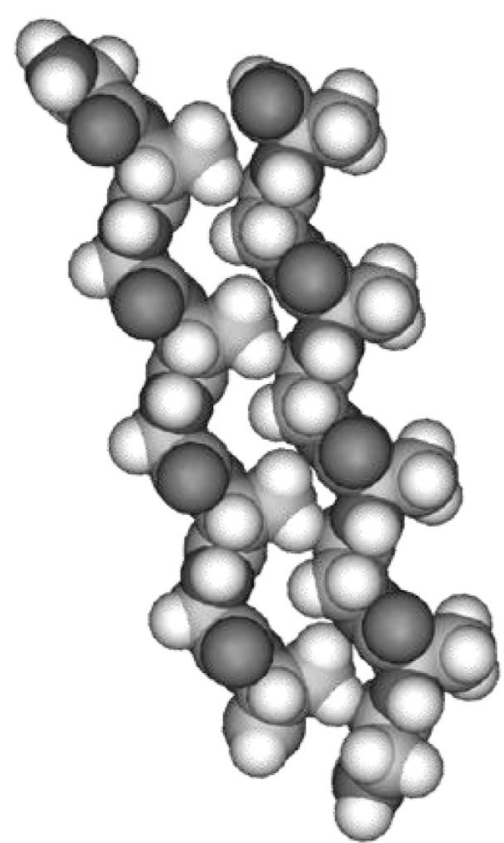

Poly gly-ala

Figure 6.

Computer models of the poly(A) and poly(GA) segments; Reprinted with permission from [28]. 


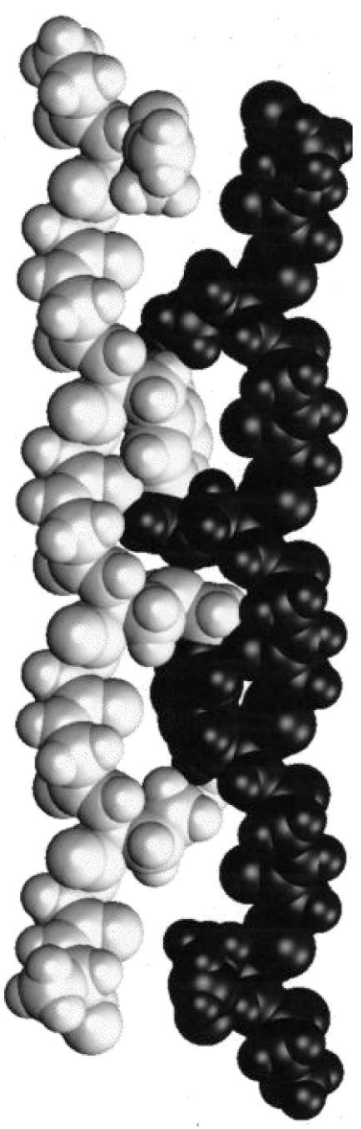

Figure 7.

Computer model of the GGX repeat region; Reprinted with permission from [28]. The model is a space-filling energy-minimized antiparallel two-strand GGS region. The starting configuration was a glycine II helix for both strands. 


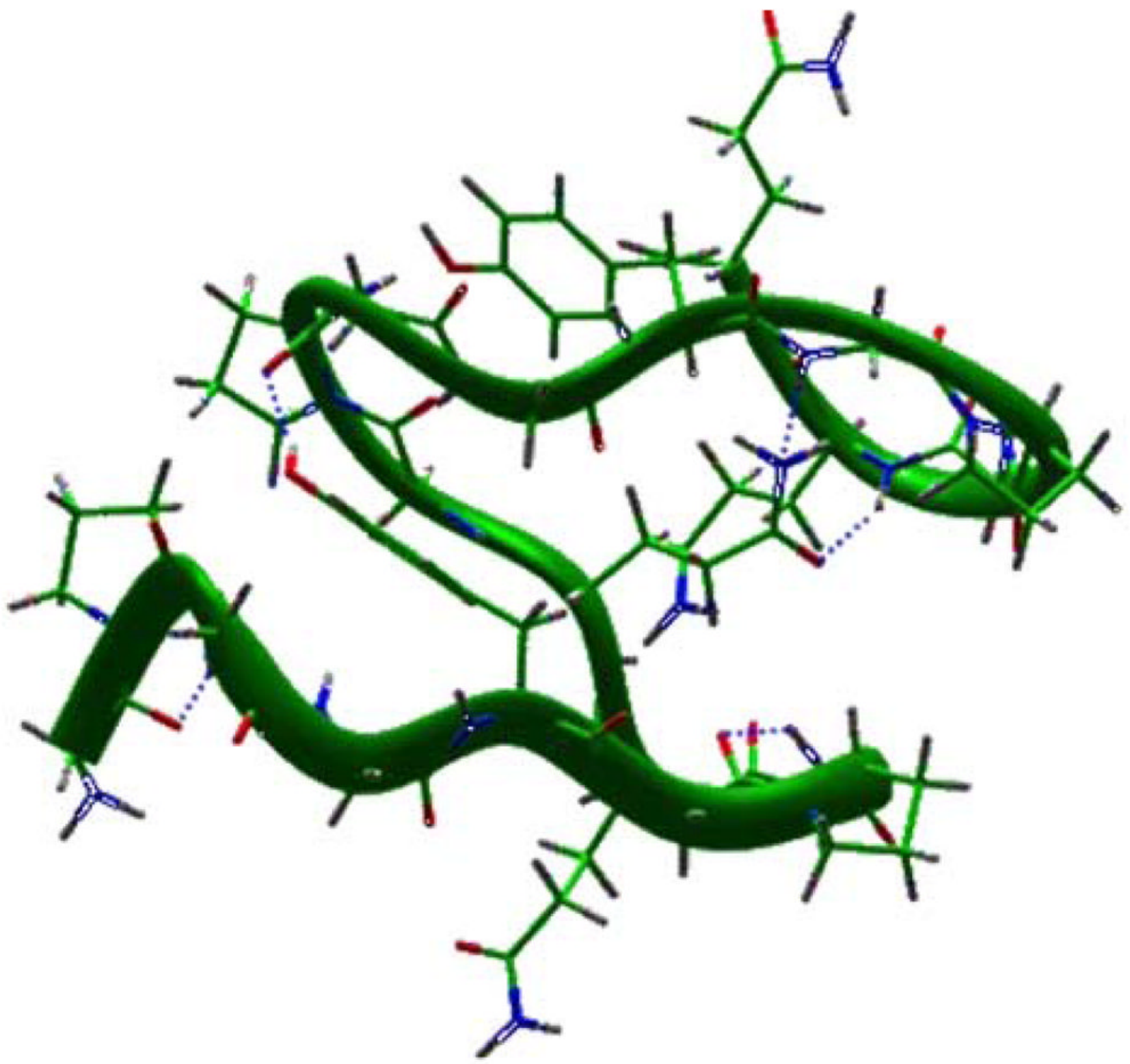

Figure 8.

Computer-generated model of a silk $\beta$-spiral; Reprinted with permission from [28] and 2012.igem.org. Computer-generated model of a pair of GPGQQGPGY repeats is shown. Hydrogen bonds (shown as dashed lines) occur between residues in the same $\beta$-turn and between different $\beta$-turns. 


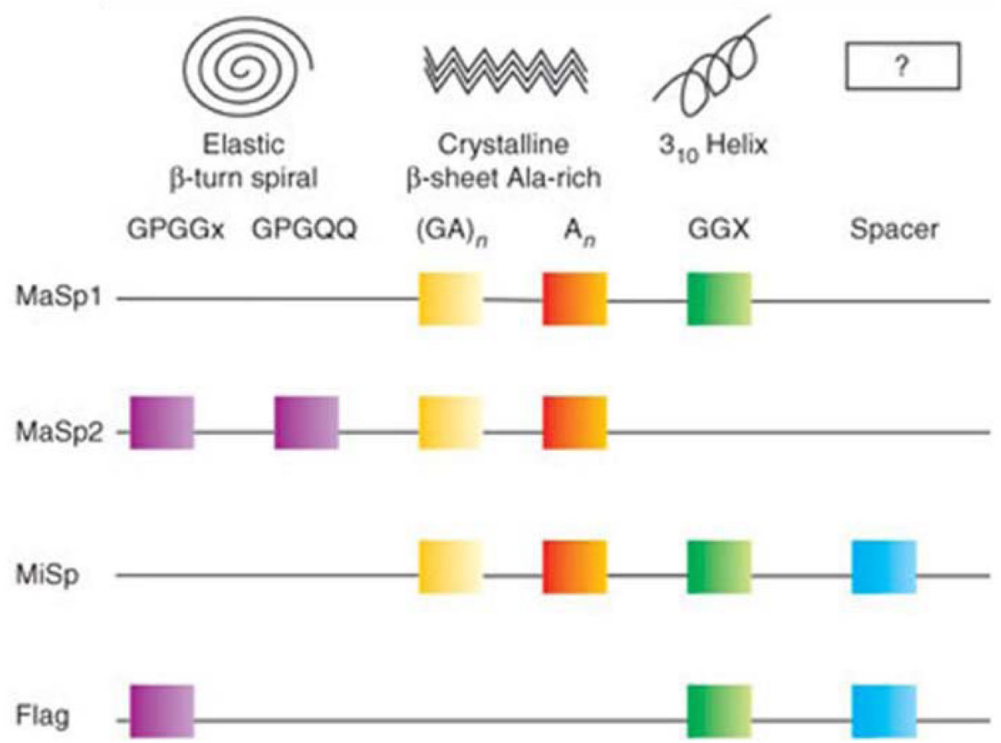

Figure 9.

Structural motifs and their secondary structures. Reproduced with permission from [116]. The empty box marked '?' indicates that the secondary structures of the 'spacer' motifs are unknown. MaSp1 or MaSp2: major ampullate spidroin 1 or 2; MiSp: minor ampullate spidroin; Flag: flagelliform protein. 


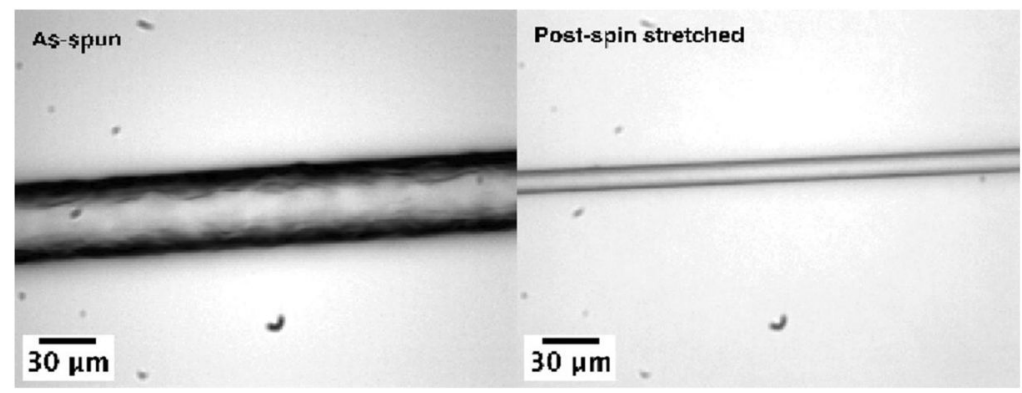

Figure 10.

Representative light microscope bright field image of fibers spun from recombinant spider silk in both demonstrating the effect of drawing on fiber dimensions. Scale bar is $30 \mu \mathrm{m}$. Reprinted with permission from [70]. Copyright 2011 American Chemical Society. 


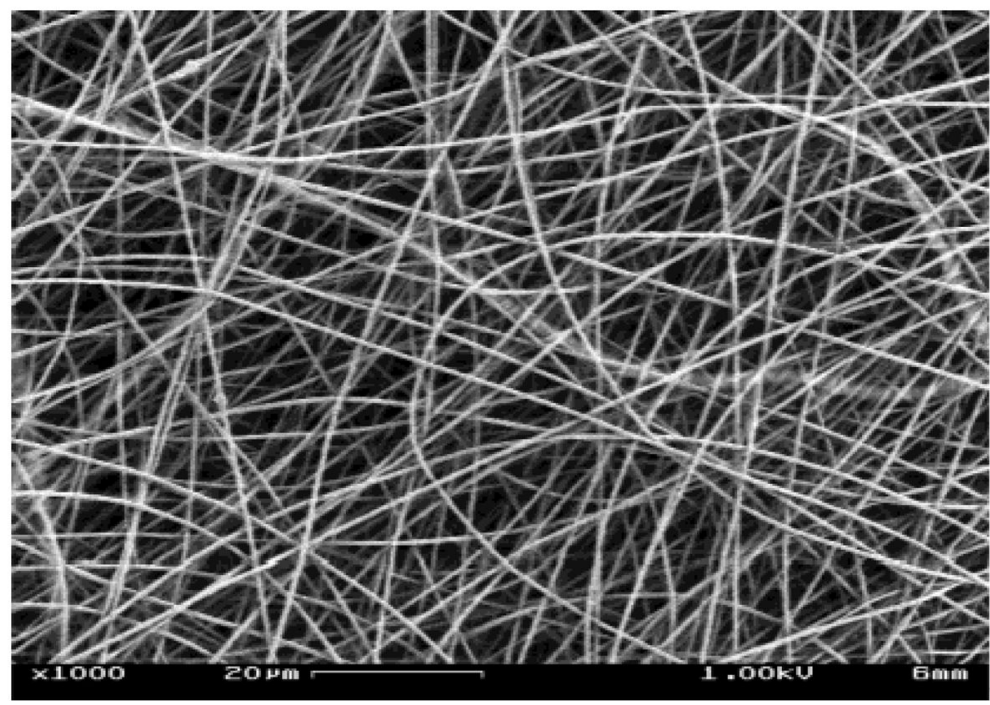

Figure 11.

Electrospun fibroin demonstrating the nanoscale and interconnected mesh generated. Adapted with permission from [73]. Copyright 2002 American Chemical Society. 


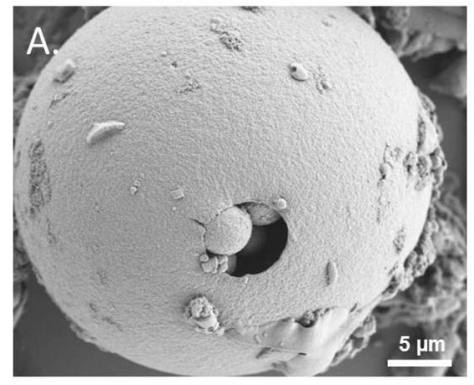

HBA6 in water - hydrophobic dominant block copolymer systems

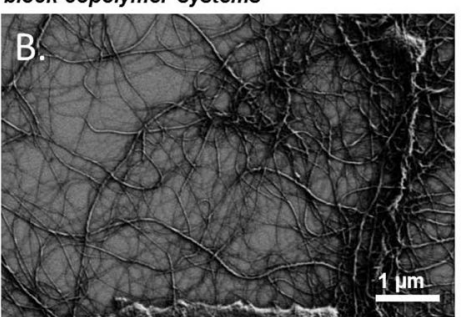

HBA2 in 2-propanol - smaller hydrophobic domain block copolymer

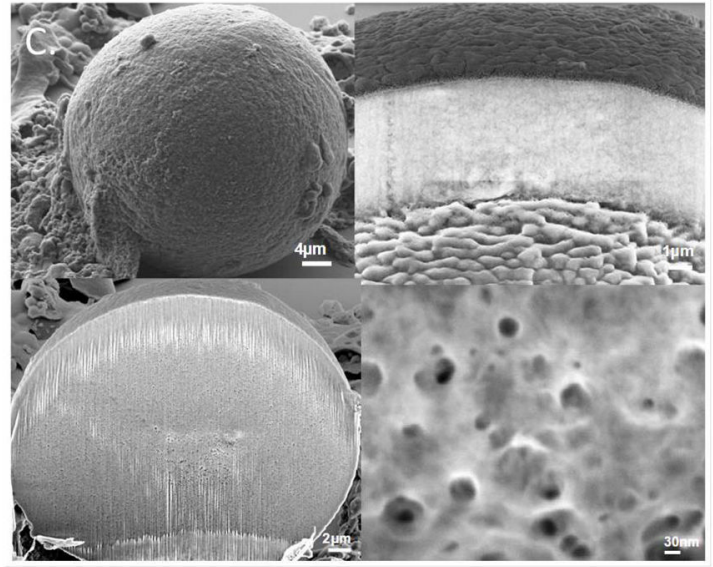

HBA6 in water forms porous spheres with an average pore size of $30 \mathrm{~nm}$

Figure 12.

Diverse molecular assemblies of spider silk-like block copolymers in water (A, C) and 2propanol (B). A block is represented by poly(A) repeats and B block is composed of GGX repeats. 


\section{A}
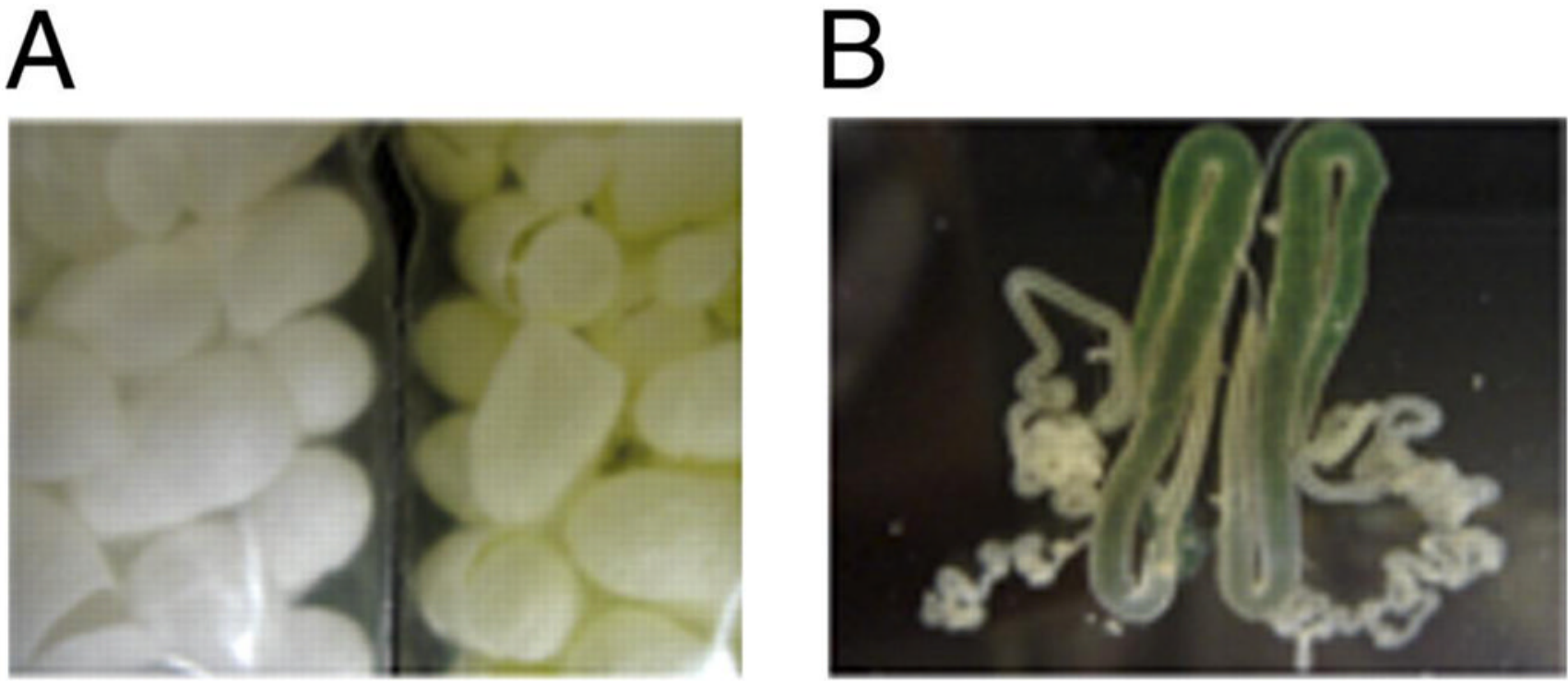

Q
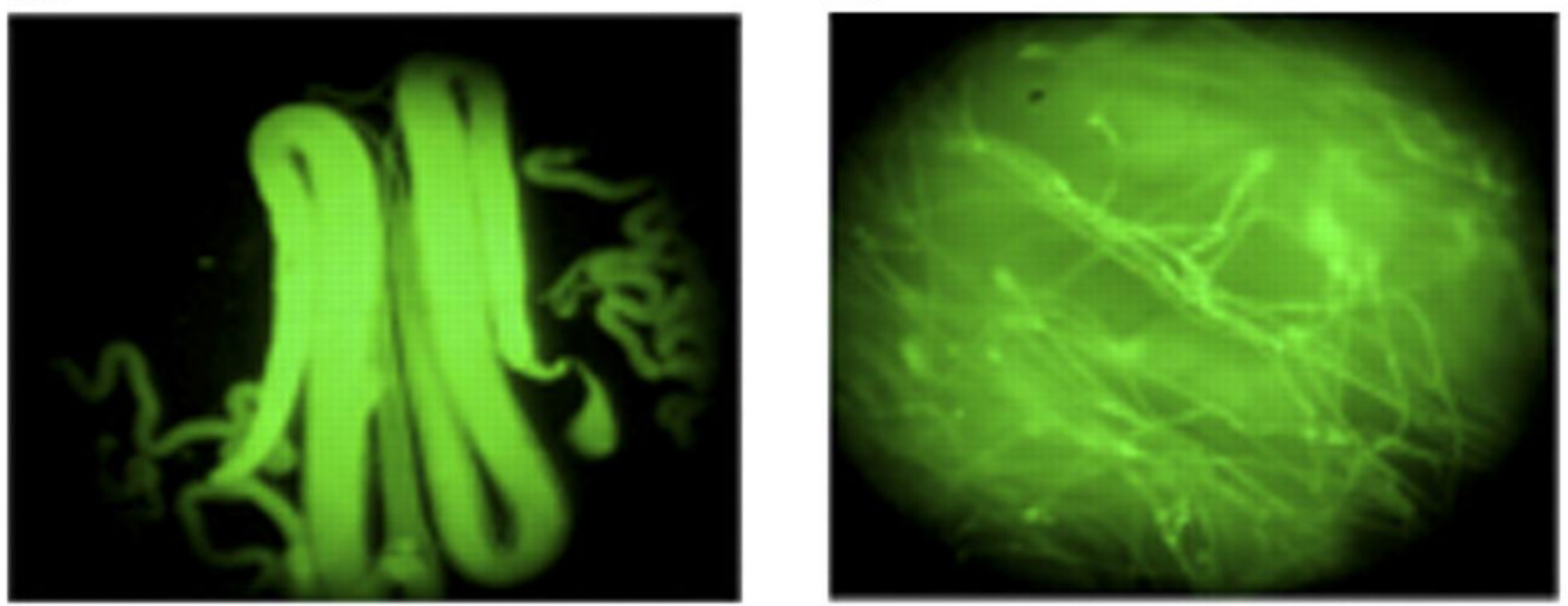

Figure 13.

Expression of the chimeric silkworm/spider silk/EGFP protein in (A) cocoons, (B and C) silk glands, and (D) silk fibers from spider 6-GFP silkworms. Reproduced with permission from [94]. 


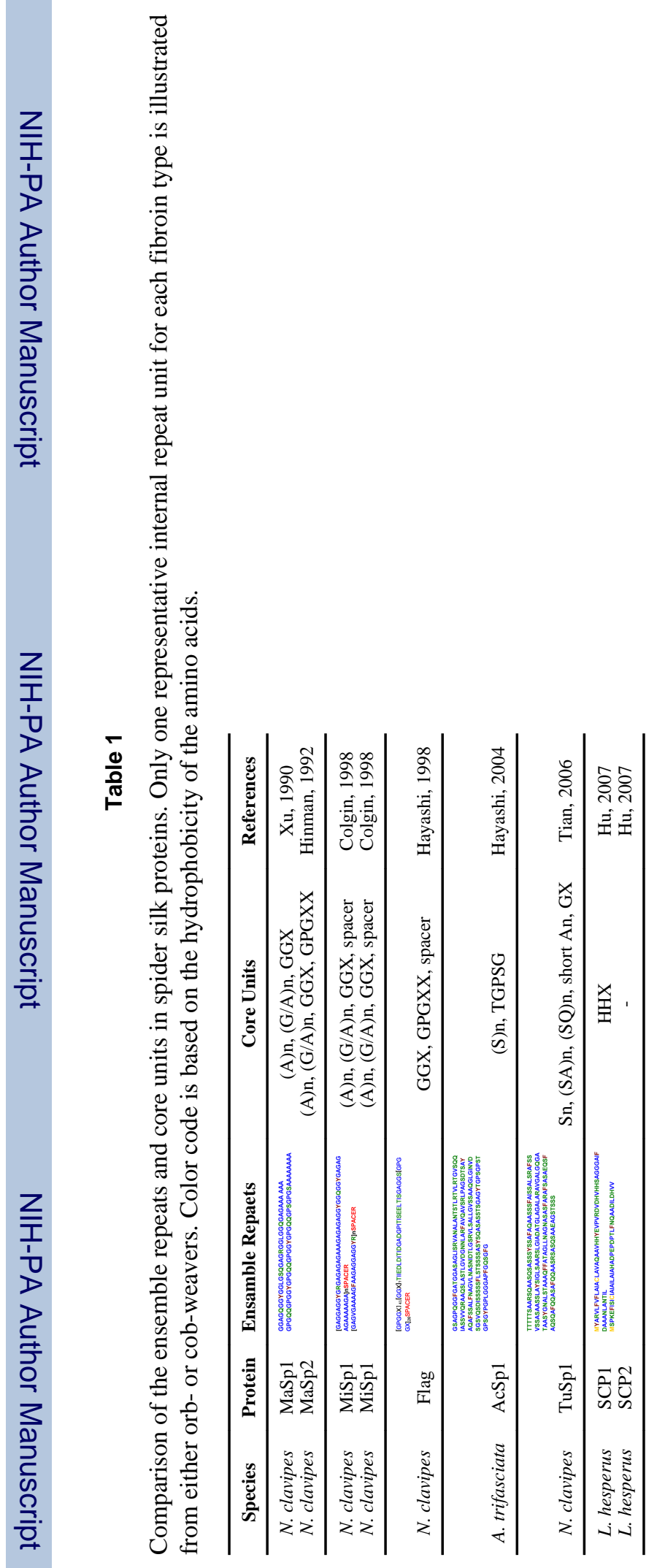


